\title{
COMET: a Lagrangian transport model for greenhouse gas emission estimation - forward model technique and performance for methane
}

The COMET transport model applied to methane

A. T. Vermeulen et al.

A. T. Vermeulen, G. Pieterse, A. Hensen, W. C. M. van den Bulk, and J. W. Erisman

ECN - Energy research Center of the Netherlands, Petten, Netherlands

Received: 13 June 2006 - Accepted: 29 August 2006 - Published: 15 September 2006

Correspondence to: A. T. Vermeulen (a.vermeulen@ecn.nl)

Title Page

Abstract

Conclusions

Tables

14

4

4

Back

Full Screen / Esc

Printer-friendly Version

Interactive Discussion 


\section{Abstract}

The Lagrangian transport model COMET has been developed to evaluate emission estimates based on atmospheric concentration observations. This paper describes the model and its application in modelling the methane concentrations at the European

5 stations Cabauw and Macehead. The COMET model captures in most cases both synoptic and diurnal variations of the concentrations as a function of time and in absolute size quite well. The explained variability by COMET of the mixed layer concentration for Cabauw varies from $50 \%$ to $84 \%$; for all hourly observations in 2002 the explained variability is $71 \%$ with a RMSE of $112 \mathrm{ppb}$. The explained variability for Macehead is $48 \%$. The most important model parameters were tested for their influence on model performance, but in general the model is not very sensitive to variations within acceptable limits. For a regionally and locally polluted continental site the COMET model shows only a small bias and a moderate random error, and therefore is considered to capture the influence of the sources on the concentration variations quite well. It is 15 therefore concluded that inverse methods and more specifically the COMET model is suitable to be applied in deriving independent estimates of greenhouse gas emissions using Source-Receptor relationships.

\section{Introduction}

Human emissions of radiatively active gases have risen sharply since the industrial revolution, leading to a sharp increase in the average concentrations in the atmosphere of the Earth (Houghton et al., 2001). The additional absorption of infrared radiation caused by this additional amount of gases leads to an increase of the average temperature of the tropospheric air; this is commonly referred to as the greenhouse effect, most probably leading to changes in the climate of our Earth. Natural changes in the atmospheric concentrations of greenhouse gases have been quite common on the geological time scale - e.g. Broecker (1997) and these were linked also to drastic changes

The COMET transport model applied to methane

A. T. Vermeulen et al.

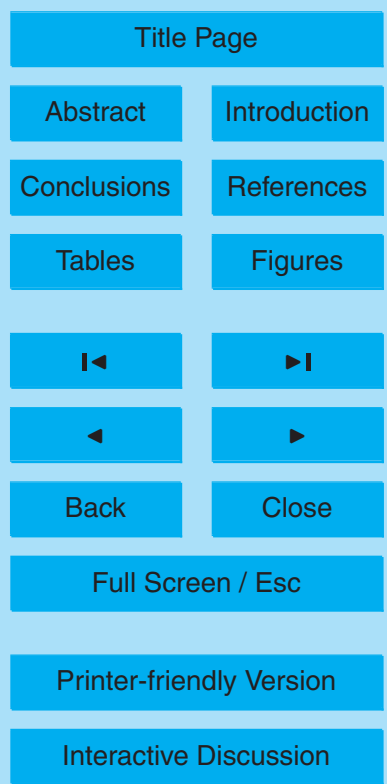


in the climate of the Earth. However, the recent changes in greenhouse gas emissions due to human activities occur at an unprecedented pace, and this pace will accelerate in the future if not appropriate measures are taken to reduce the increase of the emissions or even reduce the emissions themselves in order to stabilise the concentrations 5 of greenhouse gases at levels not too far from the current levels.

Emission reductions are needed for all four of the most important anthropogenic greenhouse gases: $\mathrm{CO}_{2}, \mathrm{CH}_{4}, \mathrm{~N}_{2} \mathrm{O}$ and $\mathrm{SF}_{6}$. Currently, the relative contribution of human induced $\mathrm{CH}_{4}$ in the atmosphere to the total human direct greenhouse effect is about $20 \%$ (Houghton et al., 2001). Of the four most important greenhouse gases, $\mathrm{CH}_{4}$ has

10 the shortest lifetime in the atmosphere ( 9 years) (Prinn et al., 1995; Houghton et al., 2001), so that emission reduction measures for $\mathrm{CH}_{4}$ will lead to changes in concentration growth rates or even a concentration decline at relatively short time-scales. This makes $\mathrm{CH}_{4}$ an attractive compound to reduce the greenhouse gas emissions.

\section{Greenhouse gas emission estimates: bottom-up versus top-down}

15 One problem with $\mathrm{CH}_{4}$ emissions is that there are also significant natural sources of methane. Atmospheric chemistry and oxidation in the soil also influence the atmospheric concentrations (Prinn et al., 1995; Ridgwell et al., 1999). Both processes and the natural emissions are in turn influenced by the changes in climatic circumstances (temperature, soil water content). There are still considerable uncertainties in the mag20 nitude of the contribution of several large (natural and human) contributions of $\mathrm{CH}_{4}$ to the global methane budget, including indications that plant materials may contribute directly to the global methane budget with no bacterial chemical conversion involved (Keppler et al., 2006).

A method independent of the current so called bottom-up inventories that can ver25 ify these emission estimates top-down over large areas would be very helpful, and may even allow to reduce the emission uncertainties. One of the methodologies that potentially can verify greenhouse gas emission budgets for large areas containing a

The COMET transport model applied to methane

A. T. Vermeulen et al.

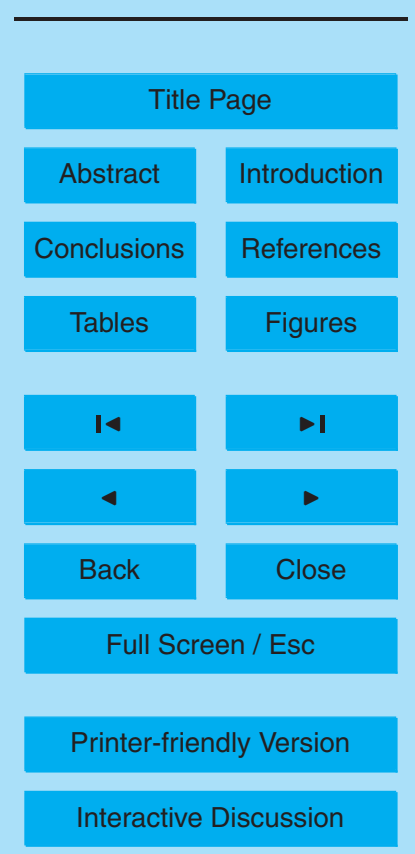


multitude of (natural and human) sources, is the use of a combination of atmospheric observations of concentrations and transport models. These methodologies will be applicable to methane but also in more or less modified form to other compounds like $\mathrm{CO}_{2}, \mathrm{~N}_{2} \mathrm{O}$ and $\mathrm{SF}_{6}$.

5 Once emitted into the air, gases are transported through the atmosphere, following the patterns determined by large scale weather systems. Eventually, all gases end up being completely mixed trough the whole atmosphere. The mean processes determining the mixing are: turbulent dispersion, convection, subsidence, lifting and advection. All these processes act on other typical scales in time and space. Irregular10 ities in emission strengths and/or removal processes however, will cause stable mean (e.g. latitudinal) gradients within the atmosphere.

Because atmospheric transport integrates over all surface sources and sinks, measurements of atmospheric concentrations can be used to quantify (net) surface fluxes over large scales by matching them with simulation predictions obtained with atmo15 spheric transport models. This approach is known as inverse modelling (e.g. Heimann and Kaminski, 1999, Bousquet et al., 1999). The rate of success of applying this approach is highly dependent on the quality of the models and on the quality, number and spatial density of the monitoring stations. The current atmospheric global observation network consists of about 100 stations. The sampling in this network is based on discrete biweekly flask observations; the emphasis in this network is on $\mathrm{CO}_{2}$ measurements and most observation sites are remote oceanic or high altitude background locations (Conway et al., 1994; see also GLOBALVIEW- $\mathrm{CO}_{2}$, 2004). Consequently, the emissions of the continents remain very poorly constrained in inversions, which as an example for $\mathrm{CO}_{2}$ leaves the nature of a Northern Hemispheric sink and its partitioning between ocean and land, and between the Eurasian and the North-American continent controversial (Fan et al., 1998; Rayner et al., 1999; Bousquet et al., 2000; Rödenbeck et al., 2003). The resolution of atmospheric transport models mostly used for global inverse modelling is on the order of $2.5^{\circ} \times 2.5^{\circ}$ degrees longitude by latitude or less (e.g. the models used in TransCom, see Gurney et al., 2002). Because of

The COMET transport model applied to methane

A. T. Vermeulen et al.

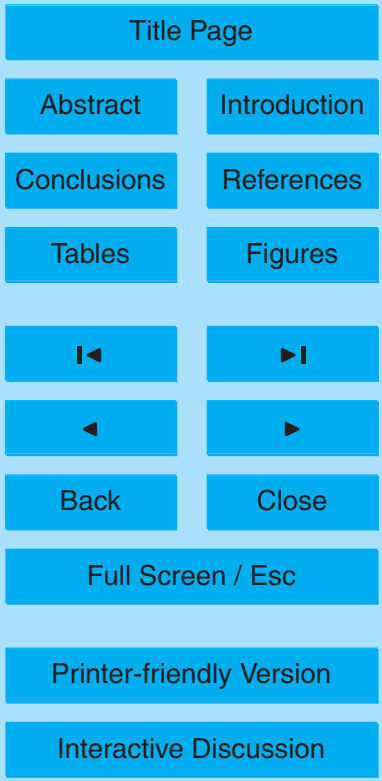

EGU 
the spatial and temporal heterogeneity of surface fluxes on land this resolution will not be sufficient to reduce uncertainties of land sources and sinks by employing the new continental measurement data. It can be expected that higher resolution (mesoscale) models are able to capture the observed variability over the continents more realisti5 cally than traditional coarse grid models.

While there have been extensive inter comparisons of global coarse-resolution transport models on monthly and annual time-scales (Law et al., 1996; Bousquet et al., 1996; Gurney et al., 2002), little attention has so far been paid to model differences on synoptic to diurnal scales above the continent. Partly because coarse-resolution 10 transport models are not able to resolve the short-term variability, but also because matching observation data usually are not available. This situation is however changing rapidly with the growing availability of surface and (tall) tower based continuous observation sites on the European and North-American continent.

Usually, the misrepresentation of sub-grid scale variability by the relatively coarse 15 models is assumed to cause a random representation error in the inversion routines (e.g. Bergamaschi et al., 2005). This error is then added to the (usually also assumed random) measurement error. However, the representation error will generally cause biases (Riccio et al., 2006) due to systematic errors besides the random errors. The treatment of measured data as predictors of cell-averaged values therefore requires a more sophisticated approach or much higher model resolutions.

Receptor oriented models like the COMET model described in this work, try to avoid this pitfall. Observations of concentrations in the atmosphere will always contain a mixture of signals from different sources at different locations and times. When measurements are available at time intervals of less than one per hour, the time scales of the signals that are superimposed on one and another can be divided in:

- the global background mean (time scale: one year)

- the latitudinal mean gradient (time scale: month)

- the synoptic average elevation (time scale: week)

The COMET transport model applied to methane

A. T. Vermeulen et al.

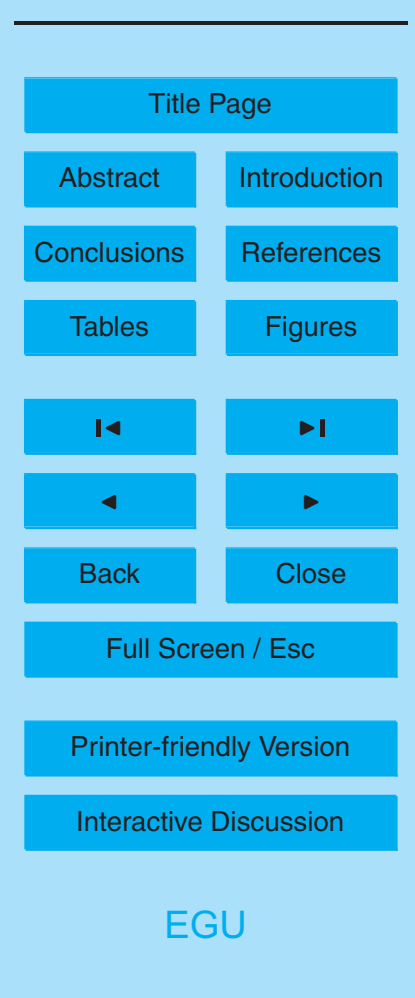


- the contribution of regional sources within 200-2000 km distance (time scale: few days)

- the contribution of local sources within say $100 \mathrm{~km}$ (time scale: few hours)

In practise, there are no clearly defined cut-off limits that allow for a sharp separation of these temporal and spatial scales and the definition used here is based more on practical insights and experience. The global observation system in place for monitoring the concentrations of the greenhouse gas concentrations, as described in the previous section, has been devised in such a way that the signal of local, regional and synoptic time scales is minimal. As a result of this strategy the measurement locations are all rather remote sites with air travel times to the areas with large emissions of at least one to several days. The main disadvantage of the data sets obtained by these stations is that it contains a mixed signal representative for continental or even larger areas and that this signal is very diluted, leading to high requirements for measurement precision.

In order to derive emissions from concentration signals with relatively high spatial 15 resolution it will be necessary to measure more closely to the source regions. The problem is that in this case the atmospheric concentration signal will contain information on all mentioned temporal and spatial scales. Use of a high resolution atmospheric transport model to estimate the influence of atmospheric dilution processes is then required.

20 The mathematical reversibility of the atmospheric mixing processes is however limited due to their chaotic nature (Lighthill, 1986; Pine et al., 2005). The resulting unpredictability and irreversibility at larger temporal and spatial scales requires that the source signal is captured close to the sources in order to allow for model inversions of that signal, before the signal is irreversibly lost in random noise. It is hard to define the maximum time period over which source information remains visible in the atmospheric signal. High-resolution Lagrangian model experiments show that the atmosphere can carry coherent high concentration signals for periods up to about 10 days and for distances up to several thousands of kilometres (Vermeulen et al., 2001; Stohl et al.,

The COMET transport model applied to methane

A. T. Vermeulen et al.

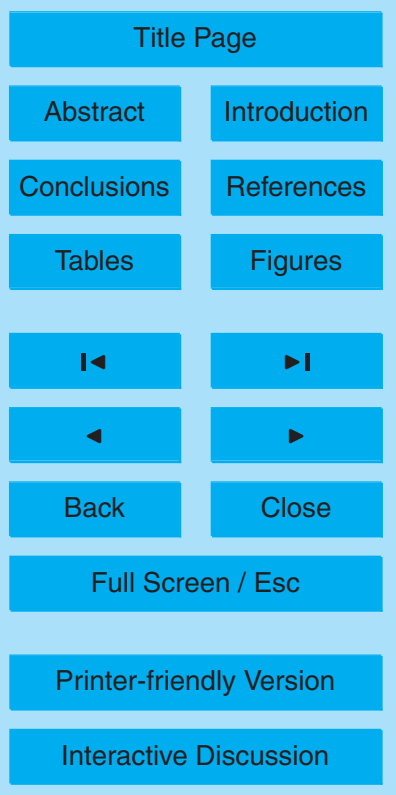


2002), often along frontal systems in extended filament structures.

In this paper we will use an updated version of the COMET model, a Lagrangian model that follows single air mass trajectories (Eisma et al., 1995; Vermeulen et al., $1999,2001)$ to capture the main variability of methane concentrations observed within 5 major source areas like NW Europe. In a future paper we will discuss the use of this COMET model to infer by an inversion technique the spatially resolved fluxes of methane for a large area. In this paper we will concentrate on the performance of the COMET model in forward concentration simulations using a predefined emission map, as decent forward performance is the first requirement for successful inversion

10 of atmospheric observations into spatially resolved emissions with minimal systematic artefacts. A further advantage of the COMET model is the limited amount of computing resources needed for even very detailed simulations, as the calculations are efficiently restricted only to those influencing the modelled receptor point, as compared to the gridded Eulerian frameworks that scale unfavourably with higher resolutions in time 15 and space. In the current setup the COMET model runs on state of the art personal computers and a full year simulation of hourly concentration for one receptor point only takes a run-time of a few minutes.

\section{Description of the COMET transport model}

\subsection{Basic setup}

20 The COMET $\left(\mathrm{CO}_{2}\right.$ MEthane Transport) model is a Lagrangian model that can be used for both predictive and inverse modelling purposes. COMET uses backward trajectories to establish the source-receptor relationship, the so-called source-receptor matrix (SRM). The calculations described in this paper were performed using trajectory and mixing layer height data derived from three nested grids with 3-hourly resolution ECMWF analysed operational meteorological data. The vertical resolution used is T61.

Using these meteorological data, the 3-D $144 \mathrm{~h}$ backward trajectories were calcu-

The COMET transport model applied to methane

A. T. Vermeulen et al.

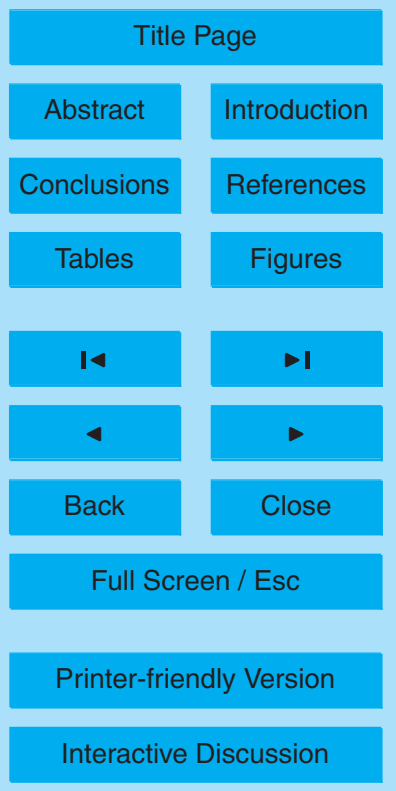

EGU 
lated from the ECMWF wind fields using the Flextra model (Stohl and Thomson, 1999). Central part of the model approach for COMET is the following linear system:

$$
\Delta \boldsymbol{x}_{k}=\mathbf{c}_{k l} \boldsymbol{e}_{l}
$$

where $\Delta \boldsymbol{x}_{k}$ is the differential measurement vector [ppm] as a function of the source5 receptor matrix $\mathbf{c}_{k l}\left[\mathrm{~s} \mathrm{~m}^{2} \mathrm{~kg}^{-1}\right]$ and the emission vector, $\boldsymbol{e}_{/}\left[\mathrm{kg} \mathrm{m}^{-2} \mathrm{~s}^{-1}\right] . k$ is an index for the measurement times; / is an index for the emission areas. For clarity, the index notation is used. The differential measurement vector is defined as:

$\Delta \boldsymbol{x}_{k} \equiv \boldsymbol{x}_{k, m}-\boldsymbol{x}_{k, b}$

where $\boldsymbol{x}_{m}[\mathrm{ppm}]$ is the actual measurement vector and $\boldsymbol{x}_{b}[\mathrm{ppm}]$ is the background concentration vector. The background concentration vector is initialised to some chosen background concentration data at the starting point of the trajectory,

$x^{-}\left(t_{n-k}, y\right)$

Here it is assumed that the temporal scales of the background and source contributions are sufficiently discernible.

15 To account for mixing of the source signal in the planetary boundary layer with the free troposphere, two vertical layers are distinguished, a mixing layer and a reservoir layer. The initial methane concentration at the start of each trajectory is taken in this case from the two-weekly averages of the calculated methane concentrations of the TM2 GCM (Heimann, 1996) for 1995 as calculated by Houweling et al. (1999). The height $\left(H^{m}[t]\right)$ of the well-mixed layer in contact with the surface varies as a function of atmospheric stability. All emissions are first accumulated in this mixed layer and when the mixed layer height changes, mass transfer takes place with the reservoir layer.

The area that influences the concentrations in the column of air in the mixed layer is assumed to be circular and the diameter of this circle is assumed to change linearly with travel time; from large at the start of the backward trajectory to small at the destination. This cone-shaped trajectory path defines a highly simplified parametrised form of the

The COMET transport model applied to methane

A. T. Vermeulen et al.

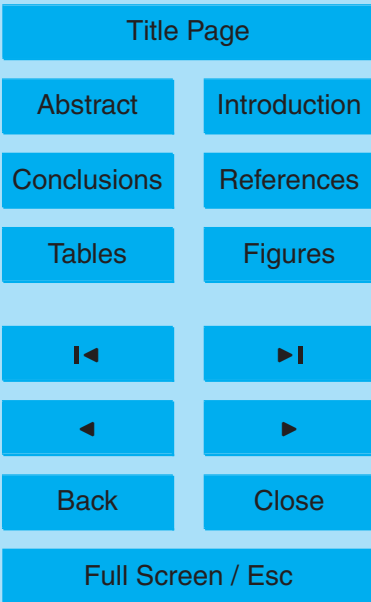

Printer-friendly Version

Interactive Discussion 
real region of influence, determined by advection, convection and turbulent diffusion. Normal trajectory models only follow an infinitesimal narrow path, ignoring the effect of turbulent diffusion along this path. An alternative to the single trajectory approach is to use an ensemble of trajectories to get at least some information on the accuracy of 5 the trajectory information and the influence of for example turbulent diffusion. This last approach will also be investigated in this research in what will be called the uncertainty trajectories analysis.

A more realistic but also computationally more demanding way to calculate the region of influence backward in time would be to perform multiple backward trajectories 10 (e.g. Stohl et al., 2002) or to use a more sophisticated Lagrangian Particle Dispersion Model (LPDM), like FLEXPART (Stohl et al., 2005) to derive the source-receptor matrix for COMET and optimise it to give satisfactory results while maintaining minimum complexity of the model. However, it is also known that the turbulent and convection schemes used for the LPDM approach are less accurate than the winds resolved by meteorological analysis (Stohl et al., 2002). The LPDM approach may very well introduce more suppression of coherent structures than actually observed. It therefore remains to be investigated whether the LPDM approach will actually improve on the approach to capture turbulent diffusion which is presented here.

In forward mode the COMET model retrieves the emissions for the grid cells under 20 the current circular source area and calculates the concentration changes and eventually composition for the modelled components in the column of air with the current mixing layer height. The height of the well-mixed layer $\left(H^{m}[t]\right)$ is determined using the bulk Critical Richardson number approach. The bulk Richardson number, Ri, is the dimensionless ratio of buoyant suppression of turbulence to shear generation of turbulence and it is usually defined as follows:

$R i=\frac{g}{\theta} \frac{\partial \theta}{\partial z}\left[\frac{\partial U}{\partial z}\right]^{-2}$

where $g$ is the gravitational acceleration $\left[\mathrm{m} \mathrm{s}^{-2}\right], \theta$ the potential temperature $[\mathrm{K}], \mathrm{z}[\mathrm{m}]$ 8735

The COMET transport model applied to methane

A. T. Vermeulen et al.

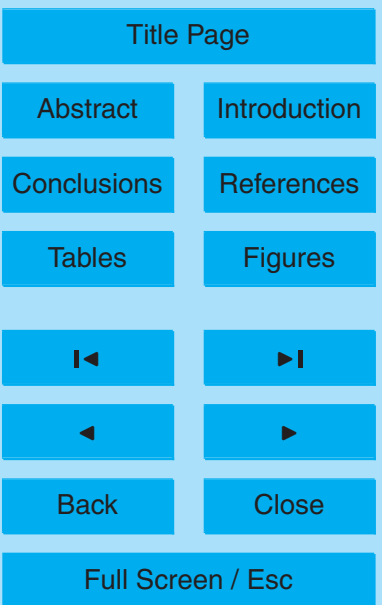

Printer-friendly Version

Interactive Discussion 
the height variable and $U\left[\mathrm{~m} \mathrm{~s}^{-1}\right]$ the horizontal wind speed. The critical bulk Richardson number is chosen as $\mathrm{Ri}_{C}=0.25$, although suggestions in the literature (Stull, 1988) range from 0.2 to 1.0. There is also some suggestion of hysteresis, where the Richardson number of a flow must drop below $\mathrm{Ri}_{c}$ before the flow becomes turbulent, where on 5 the other hand a turbulent flow can exist up to $\mathrm{Ri}=1.0$ before the flow becomes laminar. For the COMET model, it is assumed that when $\mathrm{Ri} \leq \mathrm{Ri}_{C}$, the flow will become turbulent, whereas for $\mathrm{Ri}>\mathrm{Ri}_{c}$, the flow is assumed to be laminar. ECMWF data is used for calculation of the potential temperature and horizontal wind speed gradients. An important note must be taken of the fact that the established height of the mixed layer $H^{m}[t]$ will have a significant effect on the well-mixed layer concentration calculations.

Emission data is retrieved from emission inventories per source category on a regular grid; in the case of methane the high resolution (a spatial resolution of $10^{\prime} \times 10^{\prime}$ and a 3-hourly time scale) METDAT database (Berdowski et al., 1998) is used, the base year for the emissions in METDAT is 1995.

15 The procedure for calculation of the source contributions in the SRM to the differential measurement is split into three parts:

- calculation of the contributions of the sources to the circular Areas Of Influence (Aol's) along the trajectory paths

- calculation of the vertical exchange between the well-mixed and reservoir layer due to well-mixed layer build-up or breakdown

- calculation of the contributions of the sources to the Region Of Influence (ROI) for each measurement. A ROI is defined as the complete area drawn up by the AOl's and is determined by the topology of the backward trajectory belonging to the measurement performed at a certain time and place

The following sections will explain the procedure followed for the forward calculations.

\section{ACPD}

$6,8727-8779,2006$

The COMET transport model applied to methane

A. T. Vermeulen et al.

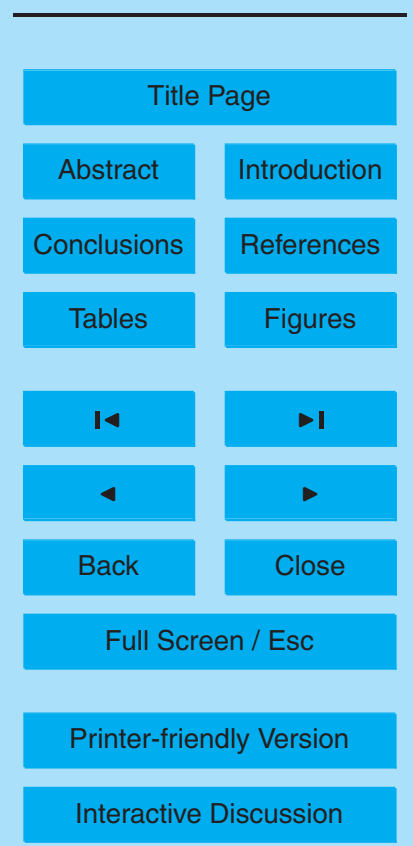


For each measurement, a backward trajectory is available. A trajectory consists of $n+1$ positions, corresponding with times $\left[t_{k-n}, t_{k}\right]$. These positions are interpolated according to the procedure illustrated in Fig. 1:

5 Interpolation is important as the mixed-layer is build up or broken down with a typical time scale in the order of minutes. This procedure ensures that the change in the wellmixed layer height at a certain model time step is small compared to the well-mixed layer height at that particular time. When the air parcel is moving at high speeds, this procedure also ensures overlap of the successive Aol's. Furthermore, vertical mixing

accumulation of the emissions by the sources occur simultaneously. Mathematically, a sufficiently small time scale enables sequential treatment of these processes.

In the this version of the COMET model, time interpolation to time scales which are an integer factor smaller than the time scale of the trajectory data $(1 \mathrm{~h})$ can be used. A cubic spline interpolation algorithm (Press et al., 1992). is used for the trajectory 15 positions whereas a linear spline interpolation scheme is used for the meteorological data along the trajectory because of the strong variability of these quantities along the trajectory.

To calculate the contribution of an individual Aol at a certain time, $t_{k-i}$, for which the surface area of the Aol is dependent of the radius of the column at that time, $r_{k-i}$, the following procedure is followed and explained in the subsequent paragraphs. First, the source grid is scanned to determine which source regions will contribute to the Aol. Then, the vertical exchange between the well-mixed layer and reservoir layer is accounted for. This exchange leads to loss of information about the preceding Aol contributions to the Rol (Region of Influence). Finally, the relative contribution of the
The COMET transport model applied to methane

A. T. Vermeulen et al.

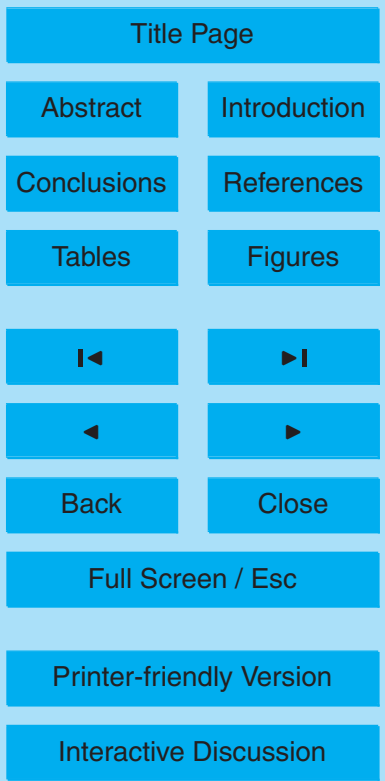




\subsection{Scanning the source grid}

The sources are first aggregated on a source grid with a resolution of $\Delta\left[^{\circ}\right]$. The spatial resolution at which the source grid is scanned, is then calculated by dividing the source grid resolution by an integer number $k$, resulting in a scan grid resolution of $\Delta_{s}=\Delta k^{-1}$

$5\left[^{\circ}\right]$. Concurrently, the circular Aol is scanned at the scan grid resolution according to the procedure shown in Fig. 2:

The indices $n$ and $m$ next to the thick grid lines represent the position in the source region grid. In this example, the thin grid lines illustrate a scan resolution five times as dense as the source region grid resolution. The algorithm will then total the number of hits per source region. The number of hits depends on the amount of scan grid cells that lie with within the boundaries of the $\mathrm{AOI}$, which is determined by its radius. The number of hits represents the effective emission grid cell surface area that will contribute to the AOI. Increasing the scan grid resolution will improve the accuracy with which the effective emission grid cell surface area is calculated, but will also incor15 porate more computational efforts. The sensitivity of the model output to changes in the scanning resolution can be easily investigated in this model setup. After completing the scan of the AOI at time $t_{k-i}$, the effective grid cell areas, $A_{k-i, u v}^{\text {eff }}\left[\mathrm{m}^{2}\right]$, can be approximated using the following expression:

$A_{k-i, u v}^{\mathrm{eff}} \cong A \frac{c_{k-i, u v}}{\sum_{u, v \in \mathrm{AOI}} c_{k-i}}$

20 where $A\left[\mathrm{~m}^{2}\right]$ is the actual grid cell area and $c_{u v}[-]$ is the number of hits in a certain grid cell with grid coordinates $(u, v)$ in the Aol. The ratio between the effective and actual grid cell area is called the area factor:

$f_{k-i, u v}^{A} \equiv A_{k-i, u v}^{\mathrm{eff}} / A \cong \frac{c_{k-i, u v}}{\sum_{u, v \in \mathrm{AOI}} c_{k-i}}$

The COMET transport model applied to methane

A. T. Vermeulen et al.

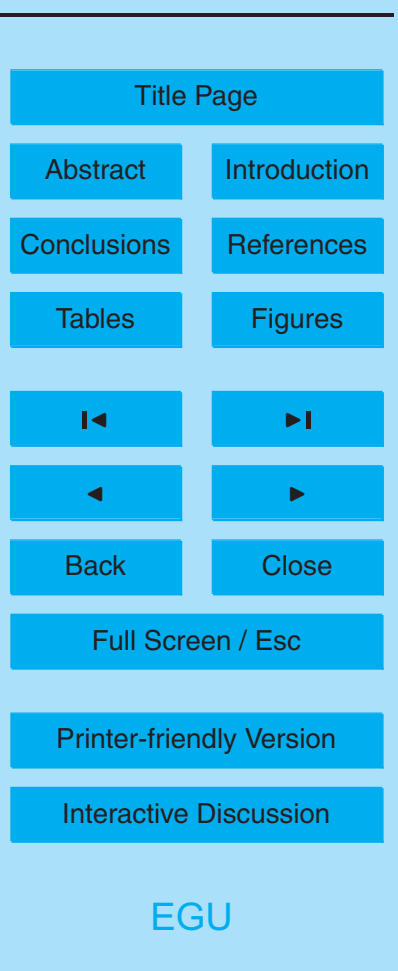


The emissions of the sources in the Aol added together using area weighting, resulting in the following expression:

$$
e\left[t_{k-i}\right]=\frac{1}{A} \sum_{u, v \in \mathrm{AOI}} A_{k-i, u v}^{\mathrm{eff}} e\left[t_{k-i}\right]_{u v}
$$

When the scan resolution is sufficiently accurate, this expression can be approximated 5 by the following expression:

$e\left[t_{k-i}\right] \cong \frac{\sum_{u, v \in \mathrm{AOI}} c_{k-i, u v} e\left[t_{k-i}\right]_{u v}}{\sum_{u, v \in \mathrm{AOI}} c_{k-i, u v}}$

\subsection{Vertical exchange calculations}

Figure 3 illustrates the covered column states for the vertical exchange calculations. Thus, in the vertical mixing calculations, the following three states are assumed:

1. the well-mixed layer height is stable. No vertical exchange between the well-mixed and reservoir layer takes place;

2. the well-mixed layer grows. In this case, air moves from the previous reservoir layer to the new well-mixed layer;

3. the well-mixed layer shrinks. Now, air moves from the previous well-mixed layer to the new reservoir layer.

Of course no exchange calculations are performed for the first state. The following expression can be written for the well-mixed layer $(m)$ and reservoir layer $(r)$ concentrations:

$x_{k-i}^{\alpha} \equiv \frac{\rho_{k-i}^{\alpha}}{\rho_{A, k-i}^{\alpha}}$

\section{$6,8727-8779,2006$}

The COMET transport model applied to methane

A. T. Vermeulen et al.

Title Page

Abstract

Introduction

Conclusions

References

Tables

Figures

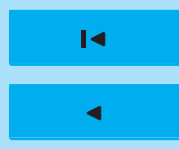

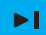

Back

Close

Full Screen / Esc

Printer-friendly Version

Interactive Discussion 
where the superscript $\alpha=[m, r]$ denotes the reference of a variable to the well-mixed layer and reservoir layer, respectively. $x_{k-i}[\mathrm{ppm}]$ is the concentration at time $t_{k-i} . \rho_{k-i}$ [mol m${ }^{-3}$ ] and $\rho_{A, k-i}\left[\mathrm{~mol} \mathrm{~m}^{-3}\right]$ are the number of moles of the species and air present per unit volume. The ideal gas law combined with the hydrostatic pressure equation 5 yields:

$\rho_{A}^{\prime m}=\frac{1}{g M_{A}}\left(p^{0}-p^{m}\right)$

and

$\rho_{A}^{\prime r}=\frac{1}{g M_{A}}\left(p^{m}-p^{r}\right)$

In these expressions, $\rho_{A}^{\prime r}\left[\mathrm{~mol} \mathrm{~m}^{-2}\right]$ is the number of moles per unit area, considering 10 a certain well-mixed height, $\mathrm{g}\left[\mathrm{m} \mathrm{s}^{-2}\right]$ is the gravitational acceleration, $p^{0}[\mathrm{~Pa}]$ is the surface pressure and $p^{m}[\mathrm{~Pa}]$ and $p^{r}[\mathrm{~Pa}]$ are the pressures at the well-mixed and reservoir layer height. The above mentioned derivation assumes isothermal conditions in the two layers. A more sophisticated derivation can be made for isentropic conditions but is not considered here. When the well-mixed layer is growing, the following expressions can be derived:

$x_{k-i}^{m}=\frac{\rho_{k-i-1}^{m}-f_{k-i}^{g} \rho_{k-i-1}^{r}}{\rho_{k-i}^{m}}$

with

$f_{k-i}^{g}=\frac{p_{k-i-1}^{m}-p_{k-i}^{m}}{p_{k-i-1}^{m}-p_{k-i-1}^{r}}$

Here, $f^{g}$ is the fraction of the reservoir layer that will mix with the new well-mixed layer that is forming. Substituting this expression together with Eq. (11) in Eq. (12) yields the

The COMET transport model applied to methane

A. T. Vermeulen et al.

Title Page

Abstract

Introduction

Conclusions

References

Tables

Figures

14

4

Back

Close

Full Screen / Esc

Printer-friendly Version

Interactive Discussion 
new concentration in the well-mixed layer:

$x_{k-i}^{m}=\frac{x_{k-i-1}^{m}+f_{k-i}^{g} x_{k-i-1}^{r}}{f_{k-i}^{g}+1}$

It is assumed that the concentration in the remainder of the reservoir layer is conserved during well-mixed layer growth. Similar expressions can be derived for the new reser5 voir layer concentration during shrinking of the well-mixed layer:

$x_{k-i}^{r}=\frac{x_{k-i-1}^{r}+f_{k-i}^{s} x_{k-i-1}^{m}}{f_{k-i}^{s}+1}$

with

$f_{k-i}^{s}=\frac{p_{k-i}^{m}-p_{k-i-1}^{m}}{p_{k-i-1}^{0}-p_{k-i-1}^{m}}$

The factor $f^{\mathcal{S}}$ is the fraction of the well-mixed layer that will mix with the new reservoir

10 layer that is forming. When the well-mixed layer is growing, the concentration in the latter layer will decrease due to the mixing with the reservoir layer. Effectively, there will be loss of information about the sources that the air parcel has seen so far. This loss of information must be accounted for while calculating the overall Rol contribution calculations. The amount of information that is lost at a certain time $t_{k-i}$ is given by the following expression:

$f_{k-i}^{s}=\frac{f_{k-i}^{g}}{1+f_{k-i}^{g}}$

When the well-mixed layer is shrinking, there will be loss of mass but no loss of information; the well-mixed layer concentration does not change in this case. Of course, the well-mixed layer concentration will not change when the layer is stable.

\section{$6,8727-8779,2006$}

The COMET transport model applied to methane

A. T. Vermeulen et al.

Title Page

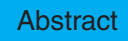

Introduction

Conclusions

References

Tables

Figures

14

$\triangleleft$

Back

Full Screen / Esc

Printer-friendly Version

Interactive Discussion 


\subsection{Aol contribution calculations}

The relative contribution of the Aol to the well-mixed layer is dependent on the instantaneous number of moles of air in the layer, thus on the layer height at that time. Recall Eq. (1) in which the enhanced concentration can also be written as:

$$
\Delta x_{k}=\sum_{i=n}^{0} \delta x_{k-i}
$$

where $\delta x_{k-i}$ is the contribution of the Aol at time $t_{k-i}$ to the enhanced concentration at trajectory arrival time $t_{k}$. The contribution of the Aol can be calculated using the following expression:

$$
\delta x_{k-i}=\frac{\delta t}{M_{s} \rho_{k-i, A}^{\prime m}} e\left[t_{k-i}\right]
$$

10 where $e\left[t_{k-i}\right]\left[\mathrm{kg} \mathrm{m}^{-2} \mathrm{~s}^{-1}\right]$ is given by Eq. (7), $M_{s}\left[\mathrm{~kg} \mathrm{~mol}^{-1}\right]$ is the molar mass of the observed species, $\delta t[\mathrm{~s}]$ is the model time step and $\rho_{k-i, A}^{\prime m}\left[\mathrm{~mol} \mathrm{~m}^{-2}\right]$ is the number of moles of air in the well-mixed layer scaled with the well-mixed layer height, given by Eq. (4). Thus, it is assumed that the well-mixed layer concentration $x_{k}$ at arrival time $t_{k}$ can be calculated by initialising with the background concentration at the starting point of the trajectory and then iteratively accounting for the mixing processes and emissions towards the arrival point at each point along the trajectory.

\section{ACPD}

$6,8727-8779,2006$

The COMET transport model applied to methane

A. T. Vermeulen et al.

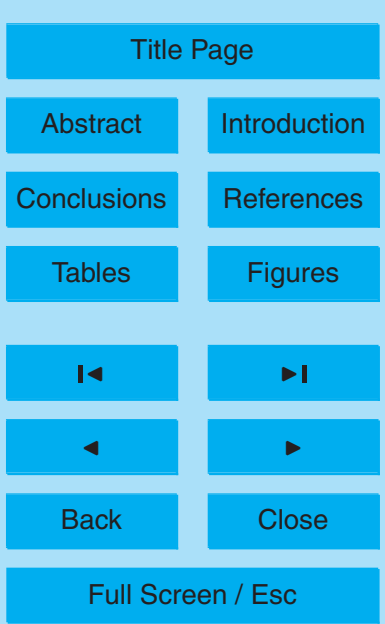

Printer-friendly Version

Interactive Discussion 


\section{Description of the input data for the COMET model}

\subsection{Concentration data}

\subsubsection{Cabauw}

Cabauw site description

5 Cabauw tower $\left(51^{\circ} 58^{\prime} \mathrm{N}, 4^{\circ} 55^{\prime} \mathrm{E}\right)$ is located near the centre of the Netherlands, $20 \mathrm{~km}$ southwest of the city of Utrecht. The Royal Netherlands Meteorological Institute (KNMI) is using this tall tower for boundary layer studies. The direct surroundings of the Cabauw tower is just below sea level in a polder area, It consists of flat meadows and ditches, with some scattered villages. On this site a $213-\mathrm{m}$ high meteorological tower is situated.

\section{Cabauw equipment and calibration}

The analytical equipment for the observation of greenhouse gas concentrations is operated by ECN and is placed in the basement of the tower. For the data used in this paper, the instruments consisted of a Carlo Erba 8000 gas chromatograph (GC), equipped with a Flame Ionisation Detector and an automated Valco valve switching system. The Cabauw GC system was also equipped with a ECD detector for measuring $\mathrm{N}_{2} \mathrm{O}$ concentrations. The configurations are specifically designed for automated ambient monitoring.

At $5 \mathrm{~min}$ intervals, a $5.0 \mathrm{ml}$ air sample is injected onto a $210 \mathrm{~cm}$ by $0.25^{\prime \prime}$ Porapak $\mathrm{Q}$

column. The analytical column is thermo stated at $90^{\circ} \mathrm{C}$. In order to optimise analytical performance, $\mathrm{CH}_{4}$ calibration is updated every 30 min by injecting two $\mathrm{CH}_{4}$ target gases. $\mathrm{CH}_{4}$ data-acquisition and initial processing was performed using standard chromatography software. The raw data files are decompressed and further processed with software developed at ECN. The $\mathrm{ECN} \mathrm{CH}_{4}$ measurements at Cabauw started in 1993

The COMET transport model applied to methane

A. T. Vermeulen et al.

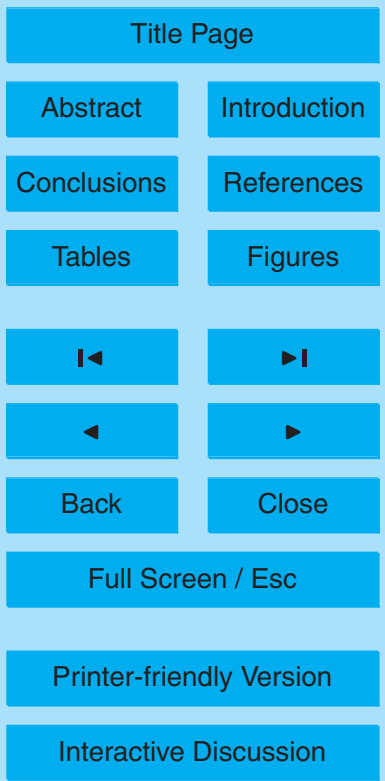


and continued until 1997, methane measurements were in this period carried out only at the highest intake level of $200 \mathrm{~m}$ a.g.I. In 1997 Cabauw tower closed down for refurbishment. In the year 2000 the measurements were restarted with an improved setup and measurement at four levels: 20,60, 120 and $200 \mathrm{~m}$ a.g.l. Air was drawn in through 5 an inlet filter and pre-dried to dew points of about $-15^{\circ} \mathrm{C}$ using Permapure $\circledR$ dryers. The sample air was drawn continuously from all four levels by $\frac{1}{4}^{\prime \prime}$ polyethylene tubing to the basement of the tower and a small fraction of the sample air is taken from the consecutive levels in a measurement cycle of $30 \mathrm{~min}$.

Two-point linear calibration curves were determined for two successive calibration 10 standards (working standards at approximately 1.8 and $2.6 \mathrm{ppm} \mathrm{CH}_{4}$ in ambient air, respectively). The concentrations of the atmospheric samples that lie between the two calibration standards were calculated with each updated calibration curve. From each group of three air samples, the 30-min average concentration was calculated and stored in a concentration file, together with date and time (UTC) of the measurement. 15 Net chromatograph peak areas of the calibration standards were stored in a calibration file, together with the date and time (UTC) of the calibration measurements.

The $\mathrm{CH}_{4}$ calibration standards were calibrated approximately 3 times each year against $\mathrm{CH}_{4}$ station standards of the National Oceanographic and Atmospheric Administration (NOAA-scale). $\mathrm{CH}_{4}$ concentrations of the working standards are calculated after 4 successive injections. The concentration range of NOAA calibration standards is 1.7 and 3 ppm.

The accuracy of the measurements, based on multiple injections of the NOAA ESRL calibration standards, is estimated to be about $4 \mathrm{ppb}$ of $\mathrm{CH}_{4}$.

\subsubsection{Mace Head}

25 The observatory of Mace Head is located on the west coast of Ireland. The station offers westerly exposure to the North Atlantic ocean (clean air sector, 180 degrees to 300 degrees) and during over $60 \%$ of the time, the station receives air masses under Northern Hemispheric background conditions. During the remaining part of the time,

The COMET transport model applied to methane

A. T. Vermeulen et al.

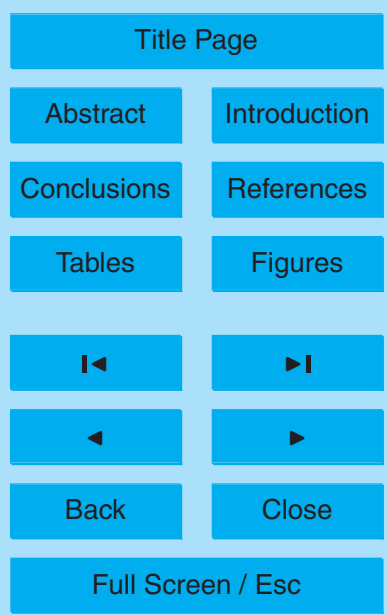

Printer-friendly Version

Interactive Discussion 
European continental emissions influence the concentration records (Simmonds et al., 1996; Biraud et al., 2000). The site location, at $53^{\circ} 20^{\prime} \mathrm{N}, 9^{\circ} 54^{\prime} \mathrm{W}$, is in the path of the mid-latitude cyclones, which frequently traverse the North Atlantic. It is $88 \mathrm{~km}$ west of Galway city (population approximately 60000 ), which is the nearest major conurba5 tion. The main Atlantic shipping lanes are over $150 \mathrm{~km}$ away, while the transatlantic air corridors are over $80 \mathrm{~km}$ away. There are three small islands offshore which are within the clean sector, but these are uninhabited and do not appear to influence any of the measurements performed at the site. Methane concentration measurement are performed at Macehead in the framework of the ALE/GAGE project (Prinn et al., 2000) 10 and consist of hourly continuous high precision measurements by GC-FID detection. The observational data used in this paper have been retrieved from the CDIAC ftp server: http://cdiac.ornl.gov/ftp/ale_gage_Agage/AGAGE/gc-md/complete/macehead/.

\subsection{Emission data}

METDAT (METhane DATabase) is a high-resolution database for $\mathrm{CH}_{4}$ emissions that 15 has been developed for the Netherlands and the Northwestern part of Europe. It has a spatial resolution of $5 \times 5 \mathrm{~km}^{2}$ and $10 \times 10^{\prime}$ (about $10 \times 20 \mathrm{~km}^{2}$ ), respectively (Berdowski et al., 1998). The countries covered in the METDAT database are Belgium, Denmark, France, Germany, Ireland, Luxembourg, The Netherlands, Norway, Sweden and the United Kingdom. For the remaining regions the values for the emissions are derived 20 from the EDGAR database version 2.0 (Olivier et al., 1996). Both data sets are based on the inventories in the year 1995. The annual average emissions as contained in the METDAT database are shown in Fig. 4. Please note the logarithmic scale of the emissions, needed to depict the vast range of the magnitudes of the emissions, with clear hotspots above densely populated and the coal mining areas.

25 The following source categories have been included in the database: enteric fermentation, animal waste, oceans, coastal waters, lakes, rivers, wetlands, biomass burning, rice paddies, landfills, gas and oil exploration, gas transport, gas distribution, waste water treatment, coal mining and combustion processes.

\section{5}

\section{The COMET transport model applied to methane}

A. T. Vermeulen et al.

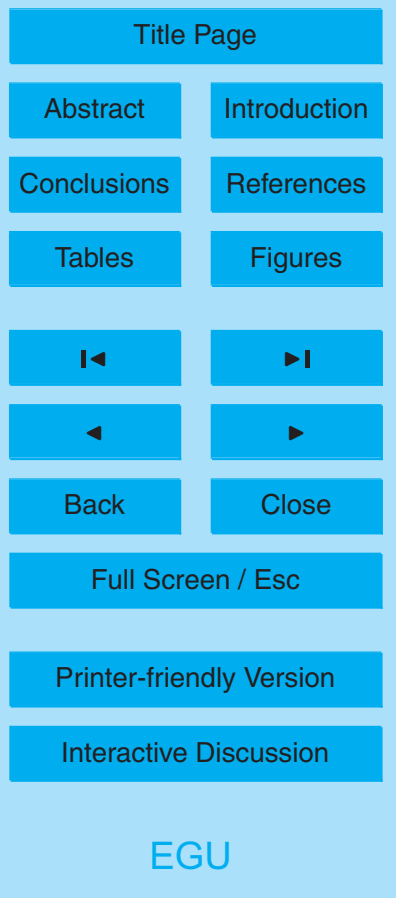


Emissions were estimated from information on emission factors and activity data. Also, data required for spatial apportioning have been applied. For each source category, an estimate was made for the temporal variation in emissions. Emission variation between years and months as well as within weeks and days has been determined. For 5 each source category, an estimate was made for the uncertainty in the emission estimate. This information was considered necessary for optimal validation of the emission database using model and measurement results. Moreover, an assessment was made of differences with emission estimates from the National Communications of the different countries.

10 In Table 1 the emissions in the Netherlands and NW Europe are presented as well as the relative contribution of the different source categories.

The $\mathrm{CH}_{4}$ emissions in the Netherlands sum up in METDAT to $982 \mathrm{Gg}$ (kton) in 1994. The $\mathrm{CH}_{4}$ emission in the Northwestern part Europe summed up to 17.6 Mton in 1994.

As can be seen in Table 1 the relative contributions of the different source categories to the total methane emissions in the Northwestern part of Europe differ slightly from the relative contributions of the different source categories to the total methane emissions of the Netherlands. The relative contribution of enteric fermentation, animal waste and the distribution of natural gas were found to be smaller. In contrast, in Northwestern Europe coal mining was contributing to a considerable extent to the

total $\mathrm{CH}_{4}$ emissions. Coal mining was and still is absent in the Netherlands. Source categories most important for the $\mathrm{CH}_{4}$ emissions in NW Europe usually show relatively small potential error, i.e. $20 \%$ for enteric fermentation, $30 \%$ for the production of natural gas and oil and $50 \%$ for landfills, the distribution of natural gas and coal mining. Relatively large potential error is estimated for the $\mathrm{CH}_{4}$ emissions from freshwater, oceans, coastal waters and waste water treatment but these sources only contribute a small amount to the total $\mathrm{CH}_{4}$ emissions in The Netherlands. Using error propagation, the uncertainty in METDAT with respect to the total yearly averaged $\mathrm{CH}_{4}$ emissions of NW Europe, was estimated to be approximately $20 \%$ (Berdowski et al., 1998).

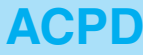

6, 8727-8779, 2006

The COMET transport model applied to methane

A. T. Vermeulen et al.

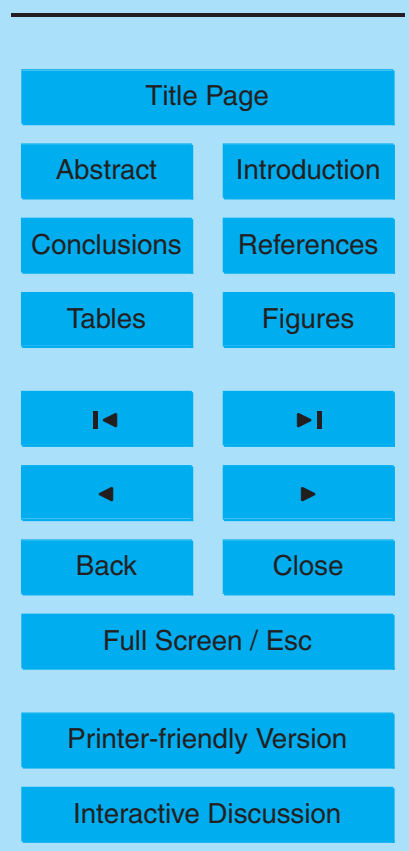




\subsection{Meteorological input}

The meteorological data used for the backward trajectory and well-mixed layer height calculations, are the analysed 3-D fields for wind, temperature, humidity and the surface fields for wind speed and direction at $10 \mathrm{~m}$, temperature at $2 \mathrm{~m}$, precipitation, cloud

5 cover, incoming solar radiation, surface stress, heat flux, latent heat flux and roughness length of the ECMWF operational model. The data has been retrieved from the operational ECMWF MARS archive using customised versions of the scripts and software provided for the Flextra and the Flexpart models. The grid specifications are shown in Table 2. The standard calculations used in this paper were based on the meteoro10 logical data in nest 1 only, and so used a horizontal resolution for the meteorological information of one by one degree.

\subsection{Background concentration data}

The concentration of methane at the start of each trajectory is taken from a database of modelled background concentration data, as calculated with the TM2 model by 15 Houweling et al. (1999). The emission provided consist of two-weekly averaged concentrations at a resolution of roughly 3 by 4 degrees.

\section{Results}

\subsection{Performance for Cabauw and Mace Head using default parameters}

The COMET model was applied to simulate the hourly concentrations at Cabauw tower and Mace Head (Prinn et al., 2000) for the year 2002. Both simulations were performed using 3-D 96-h backward trajectories and meteorological data using meteorological fields at a resolution of $1.0^{\circ} \times 1.0^{\circ}$ (grid index 1 of Table 1 ). In the next chapter, the results of a sensitivity analysis for the COMET parameters to determine the best performance of the model will be shown.

The COMET transport model applied to methane

A. T. Vermeulen et al.

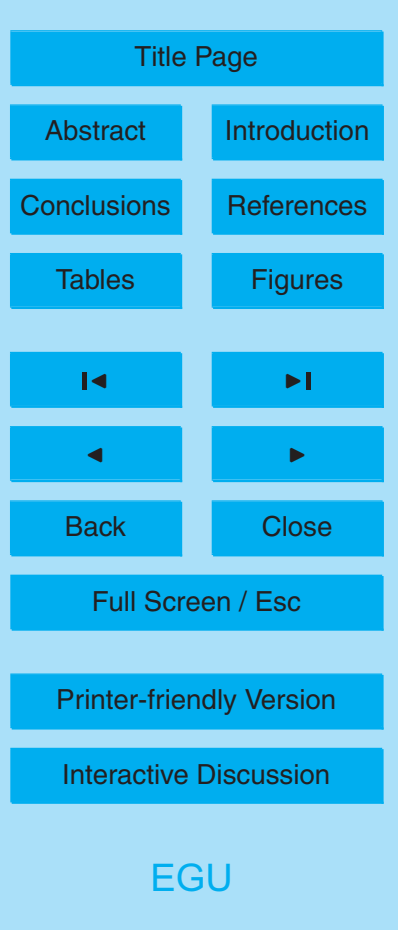


The above mentioned spatial resolution of the meteorological data and the following parameters of the model were the so called default state of the model, defined below:

- Radius of Aol at start of trajectory: $120 \mathrm{~km}$

- Radius of $\mathrm{AOI}$ at end of trajectory: $20 \mathrm{~km}$

5

- Emission database: METDAT at $10^{\prime} \times 10^{\prime}$ minute spatial resolution

- Grid scan resolution: 2 min

- Reservoir layer height: $10 \mathrm{~km}$

- Emissions do not vary with time: yearly average values are used.

The forward simulated concentrations are shown in Fig. 5 for Cabauw and in Fig. 6 for 10 four-month period. For Cabauw, the mean mixed layer concentration was calculated using the Cabauw vertical concentration profile observations along the tower, taking into account only those observations that fall within the (modelled) mixed layer.

The model captures the diurnal variation in concentration very well. Both timing and 15 height of the daily maxima and minima are realistic. Also, the synoptic variation and build-up of the concentration in high pressure anti-cyclonic conditions are represented well by the model. Figure 7 further illustrates the correlation between model and measurements. The COMET model explains about $72 \%$ of the variability in the measured concentrations at Cabauw for the whole series of hourly observations in 2002 . The magnitude higher than the measurement error. Overall, the concentrations predicted by the model above the global background of $1760 \mathrm{ppb}$ are $4 \%$ higher than the observations. This can be due to systematic errors in the model or in the underlying data, like emissions rates and well-mixed layer height.

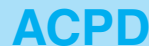

$6,8727-8779,2006$

The COMET transport model applied to methane

A. T. Vermeulen et al.

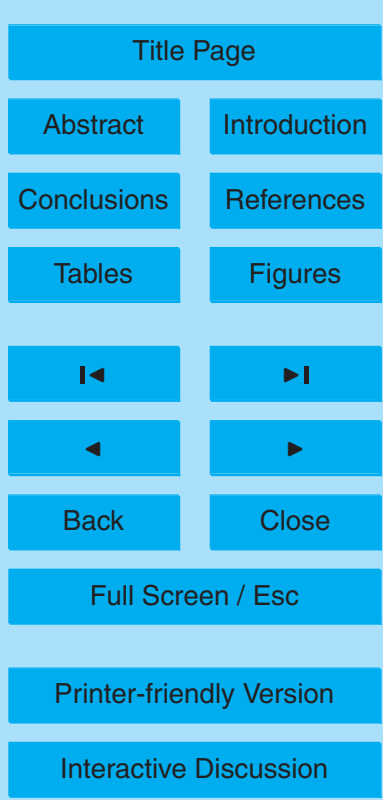


In Fig. 6 the modelled and measured hourly methane concentrations are shown for Mace Head. Here, diurnal and synoptic time scale variation are both captured reasonably well, although the correlation coefficient $\left(R^{2}=0.48\right)$ is less than for Cabauw. This is due to the fact that the Macehead measurement data is only available for the ground 5 level, while for Cabauw the mean mixed layer concentration was calculated using the Cabauw vertical concentration profile along the tower. For Cabauw, the correlation between modelled and the observed concentrations at $20 \mathrm{~m}$ Above Ground Level (a.g.I.) is in the same order of magnitude, i.e. $R^{2}=0.50$.

Figure 7 shows a scatter plot of the measured versus modelled hourly concentrations 10 of $\mathrm{CH}_{4}$ at Cabauw for the year 2002.

\subsection{Model error as a function of measurement height}

The COMET model predicts the mixed layer column averaged concentration. Observations at a single level will contain either too much or too little of the local sources information, therefore (tall) towers sites measuring vertical gradients are more useful 5 observation sites for the COMET model. From the probability density function (pdf) of the error in the hourly predicted concentrations, defined as the difference between modelled and observed absolute concentration, as depicted in Fig. 8 for the different measurement heights at Cabauw, we can see that this pdf is most symmetric and most narrow for the mixed layer concentration, with a maximum around zero. From the figure 20 we can conclude that for mixed layer concentrations the COMET model error distribution is almost Gaussian with a bias close to zero. Use of the concentrations observed at $20 \mathrm{~m}$ a.g.l. delivers a pdf for the model error that is very similar, though the distribution is slightly more skewed to negative differences (observed concentrations higher than modelled). When concentrations from higher levels are used, the distribution maxima 25 shift to negative values, with a maximum at $100 \mathrm{ppb}$ for the $200 \mathrm{~m}$ a.g.l. observation level.

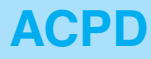

$6,8727-8779,2006$

The COMET transport model applied to methane

A. T. Vermeulen et al.

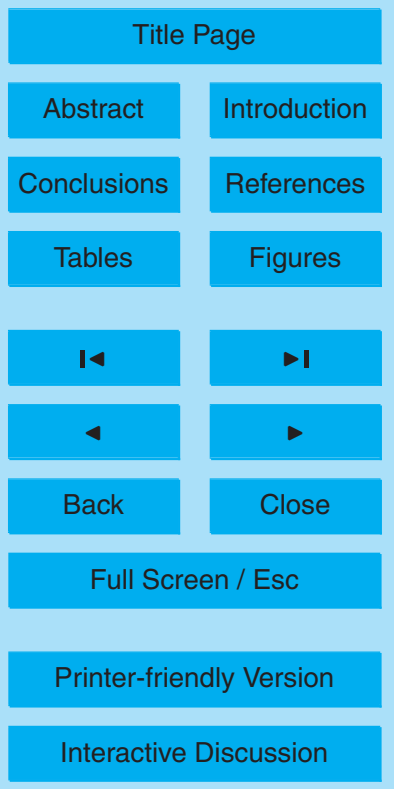


Using the default parameters for COMET, different trajectory types for arrival point Cabauw were evaluated by performing forward simulations for the following $96 \mathrm{~h}$ backward trajectories for the year 2002:

$5 \quad-3-D$ trajectories for the respective arrival heights of 20 (=default run), 60, 120 and $200 \mathrm{~m}$ a.g.l. (case 1-4)

- A mixed layer trajectory for arrival height $20 \mathrm{~m}$ a.g.l. (case 5).

- Five cluster trajectories (A-E) at equidistant points in a circle around Cabauw, at a distance of $25 \mathrm{~km}$ (case 6-10).

- Case 1 with methane emissions varying as function of time (case 11).

- Case 11 using the three nested grids of Table 1 at full resolution of $0.5^{\circ} \times 0.5^{\circ}$ (Case 12).

In Table 3 and in the following of this article, the model results are compared with measurements after removing the modelled background concentration from both measured and modelled signals. This results in slightly lower explained variability.

The results are not very sensitive to the trajectory type used. The best performance for the medium resolution trajectory information, as measured by the correlation, is obtained by using the standard trajectory information including variation of the emission with time (Case 11). The relatively lowest performance, with $6 \%$ loss of predicted vari20 ability, is obtained using the trajectory information for an arrival height of $200 \mathrm{~m}$ a.g.l.. The mixed layer trajectory for an arrival height of $20 \mathrm{~m}$ a.g.l. shows about the same performance as the standard run.

The highest performance is obtained, measured by correlation as well as by RMSE, by using the high-resolution trajectory information for the arrival height of $20 \mathrm{~m}$ a.g.l.. 25 When using trajectories with the higher resolution meteorological data, the RMSE is

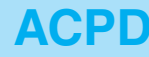

$6,8727-8779,2006$

The COMET transport model applied to methane

A. T. Vermeulen et al.

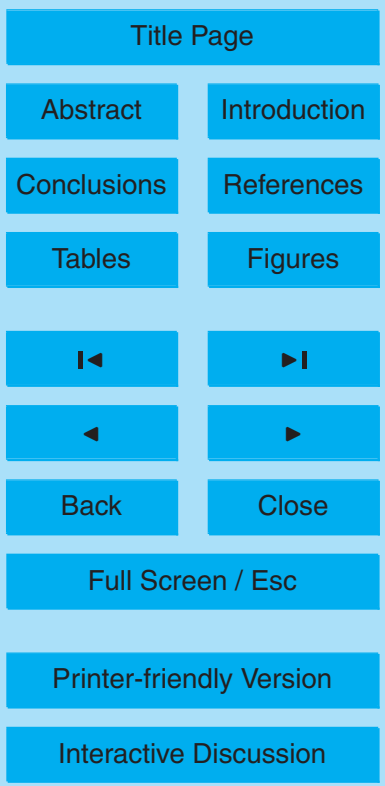

EGU 
reduced by about $20 \%$ compared to the trajectories calculated with the lower resolution meteorological data.

5.4 Evaluation of the performance of the standard run as a function of averaging and time

5 In Fig. 9 the performance of COMET in the standard run is shown disaggregated by month. Highest correlations with $\mathrm{R}^{2}$ larger than 0.80 are found in the months January, February and October, while the lowest correlations with $R^{2}$ values smaller than 0.65 are found in June and August. The RMSE values follow the correlation pattern with lower RMSE at higher correlations.

10 Figure 12 shows the performance of COMET for the standard simulation as a function of the hour of the day. Highest correlations around $R^{2}=0.85$ are found in the early morning around 08:00 UTC and in the afternoon around 15:00 UTC. A clear minimum for the RMSE of $40 \mathrm{ppb}$ is found around 14:00-15:00 UTC. The periods with lowest correlation between model and observations are the periods with the largest concentration changes with time due to rapid changes in the mixed layer height in the periods of sun rise and sun set respectively. The daily differences between night and day time mixed layer heights are largest in summer time, which could explain the lower performance of the model in the summer months, especially when these periods are accompanied by low transport speeds.

20 Figure 11 shows the performance of COMET for the standard simulation as a function of averaging time. The correlation increases steadily with averaging time with a maximum at weekly averages. In that case, a RMSE of $50 \mathrm{ppb}$ is found and a correlation $\mathrm{R}^{2}=0.85$.

Figure 12 shows the performance of COMET for the standard simulation as a func25 tion of averaging time, but now for day-time sampled values. Day-time is defined here as the time of day between 09:00 and 16:00 UTC. The correlation now does not increase clearly with averaging time and reaches its maximum at hourly averages. Then a RMSE of $20 \mathrm{ppb}$ is found with a correlation $R^{2}=0.85$. A minimum correlation of

The COMET transport model applied to methane

A. T. Vermeulen et al.

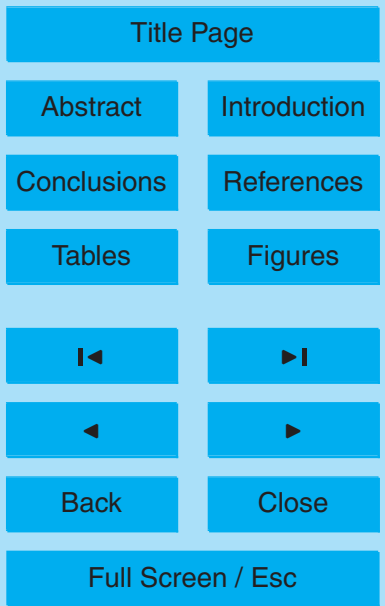

Printer-friendly Version

Interactive Discussion 
$\mathrm{R}^{2}=0.48$ is found for an averaging time of three hours.

When a sampling scheme is chosen for Cabauw like deployed in the NOAA ESRL global network (GLOBALVIEW-CO $\left.\mathrm{CO}_{2}, 2004\right)$, where grab samples are taken in biweekly intervals, the correlation coefficient $R^{2}$ drops to less than 0.50 and the slope of the best 5 fit goes from about 1.0 to 0.80 . The benefit of a continuous observation record in nonbackground conditions compared to discontinuous grab sampling is therefore obvious with an increase of explained variability of $30 \%$ and a decrease of the bias with $20 \%$.

\subsection{Influence of the radii of the Area of Influence (Aol) on the model performance}

To test the assumptions of the parametrisation of lateral diffusion through the circular 10 Aol's in the COMET model, the radii of these areas were varied using the trajectories in the default case (1) from 5 to $120 \mathrm{~km}$ at the arrival point and starting point, respectively. The results of the regression analysis between modelled values of the methane concentration and the observations are shown in Table 4. Clearly, part of the explained variability is lost when very small radii smaller than $20 \mathrm{~km}$ are used. Maximum correla15 tions are observed for an arrival radius of $40 \mathrm{~km}$. At this radius for the AOI at the arrival point maximum correlations for a start point radius of $40 \mathrm{~km}$ were found, though the differences in both correlation as well as RMSE were found to be quite small when the both radii are varied between 20 and $60 \mathrm{~km}$. A large part of the run time of the COMET model is determined by the radii of the AOl's along the trajectories. Considering the distribution of methane emission sources around Cabauw, the results support a reduction of the surface areas of the AOI to the size of 20 by $20 \mathrm{~km}$, herewith reducing the COMET run time with a factor of 3 compared to the default setting.

\subsection{Influence of the reservoir layer height on the model performance}

Another factor that might influence the COMET model performance is the assumed 25 height of the reservoir layer, as this height determines the concentration change in the reservoir layer when air and $\mathrm{CH}_{4}$ is exchanged between reservoir and mixing layer

The COMET transport model applied to methane

A. T. Vermeulen et al.

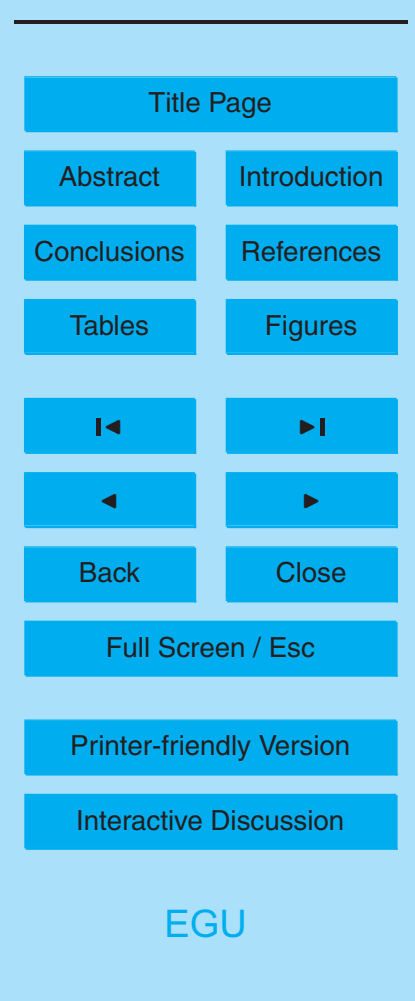


when the mixed layer height changes. The reservoir layer height setting in COMET was varied between 10 and $3 \mathrm{~km}$ and the results for the linear regression between modelled and observed concentrations are shown in Table 5. This figure clearly shows that the COMET model is quite insensitive to this parameter. In the COMET model as well as 5 in reality, most variability of concentrations takes place in the mixed layer, so that the concentrations in the reservoir layer and thereby also the trajectory for the reservoir layer are not determining the concentrations near the surface significantly.

\subsection{Influence of the spatial resolution of the emission database}

The spatial variability of the $\mathrm{CH}_{4}$ emissions in the METDAT emission database is quite 10 large (see Fig. 4). However, in the atmosphere there will always be some horizontal and vertical mixing. In the default parameter set the COMET model assumes that near the arrival point the emissions are averaged over a Aol with a radius of $20 \mathrm{~km}$. Besides this spatial averaging, temporal averaging also takes place during the build up of concentrations in the mixed layer. During day time, the resulting concentration is therefore only a weak function of the very nearby source strengths. To examine the influence of the spatial resolution of the emission database on the performance of COMET predicted concentrations versus measurements simulations were carried out using spatially averaged versions of the METDAT database. In the default mode the resolution of the METDAT database is $10 \mathrm{~min}$ ( 0.167 degrees). The simulations were carried out with resolutions of $0.5,1,2,3,4$ and 5 degrees. Figure 13 summarises the outcome of this experiment. The explained variability expressed as $R^{2}$ is only weakly influenced by the resolution of the emission database, a few percent or more of explained variability is lost at resolutions less than 2 degrees. The RMSE shows a large decrease with lower resolution, but this is explained by the lower average modelled concentrations, shown 25 here as the slope of the linear regression relation between model and observations. At emission resolutions of 2 degrees and lower at least $20 \%$ up to $70 \%$ of the concentration signal is lost. The spatial averaging of the emissions leads to low contributions to the concentrations in the mixed layer and this effect starts to become important for

The COMET transport model applied to methane

A. T. Vermeulen et al.

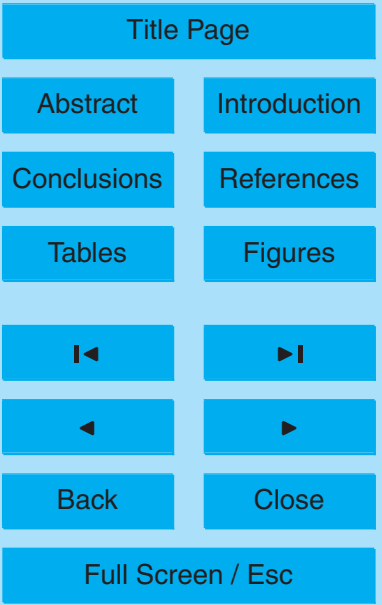

Printer-friendly Version

Interactive Discussion 
emission database resolutions of 1 degrees and lower. There is not much effect in the model results in applying a higher resolution of the emission database than 1 degree.

\subsection{Influence of the backward length of the trajectories}

As shown in the description of the COMET model in Sect. 3 the influence of source 5 areas decays with travel distance to the receptor point due to a decrease in the circular source area diameters with travel time (see Sect. 5.5, where it was shown that the influence of variation of the diameters on the model performance is rather small) and because of the dilution with air of lower concentration from the reservoir layer when the mixed layer grows during day time. High concentrations occur at Cabauw station 10 usually at night when the mixed layer is shallow and transport speeds are low, so that emissions lead to high enrichment of methane in the mixed layer. It is expected that methane picked up in the mixed layer during the night before arrival will be diluted to a high extent in the day time before arrival and this will hold even stronger for days and nights longer before that. Emissions picked up several days before arrival will hardly 15 leave a concentration "footprint" under normal conditions. However, under strong inversion events the development of the daytime mixed layer can be strongly suppressed, leading to a longer 'memory' of the atmosphere for influence of emissions. To investigate the needed length in travel time of the backward trajectories to simulate both the changes on the diurnal as on the synoptic timescale we performed simulations with truncated trajectories, shorter than the default of 96 backward hours. In these simulations the concentrations at the start of each (truncated) trajectory were taken from the background concentration database as usual. Table 6 shows the model performance as a function of the backward length of the trajectories. As expected the performance decreases with shorter trajectories, though the effect tends to be relatively small, up to a trajectory length of 36-24 $\mathrm{h}$. The RMSE values are not showing a significant influence of shorter trajectory lengths, but the explained variability expressed as the correlation coefficient $R^{2}$ is reduced by $10 \%$ for very short trajectory lengths of $12 \mathrm{~h}$. Also the slope of the best fitting regression line between observed and modelled concentra-

The COMET transport model applied to methane

A. T. Vermeulen et al.

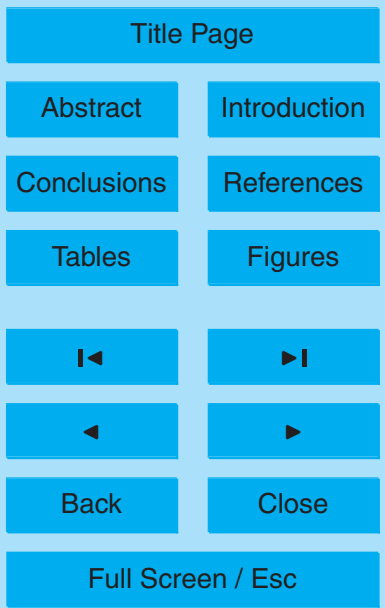

Printer-friendly Version

Interactive Discussion 
tion is reduced, which can be explained by less input of emissions into the modelled atmospheric column above the assumed background concentration.

\section{Conclusions and discussion}

The COMET model is able to reproduce most of the variability of the diurnal and syn5 optic concentration signal of methane in the atmospheric boundary layer at the observation sites of Cabauw and Macehead, where Cabauw is considered representative of a regionally and locally influenced continental observation point and Macehead is close to a background observation point with occasional regional influences. Due to the availability of information about the vertical profile of the methane concentrations, the model performs better in comparison with observations for the Cabauw tall tower site, than for the Mace Head surface level site.

The overall agreement between modelled and measured concentrations of methane is good at all timescales. Model performance is less for midnight hours and for the early morning transition hours in which the well-mixed layer grows. Highest model perforexplained variability of $84 \%$ for the whole year of hourly observations in 2002 .

For observation periods of several weeks, the COMET model shows correlations up to $R^{2}=0.90$ for the unfiltered series of hourly observations of the mean mixed layer methane concentrations.

The COMET model is very insensitive to changes in the main, and initially rather arbitrarily chosen, default model parameters like for instance the sizes of the areas of influence along the trajectories and the height of the reservoir layer. Model performance is most affected by the resolution of the meteorological input data, which determines the trajectory positions and the predicted heights of the well-mixed layer, and the use of the vertical concentration profile data as measured at the tall tower of Cabauw, compared to the use of data from the single surface observation level at Mace Head.

The COMET transport model applied to methane

A. T. Vermeulen et al.

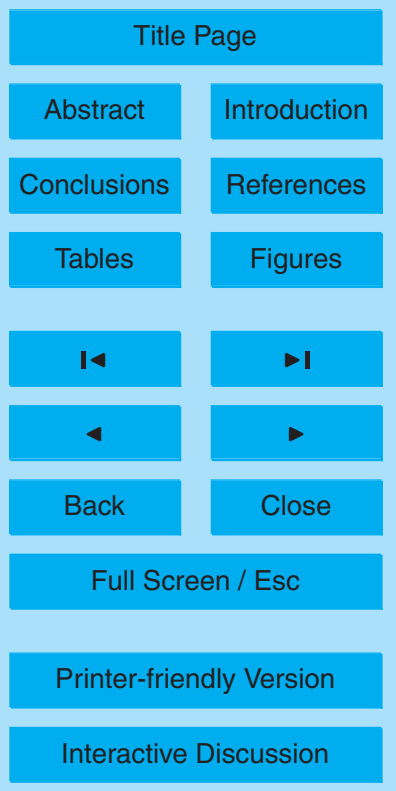

EGU 
The model is quite insensitive to the resolution of the $\mathrm{CH}_{4}$ emission database as long as the resolution is better than 2 degrees. Also the influence of variations of the emissions with time does not improve the explained variability. This result might be different for other components than $\mathrm{CH}_{4}$ and also be different for sites in less homogeneous 5 source areas.

The night time and early morning periods are the periods where we expect that the mixing layer shows the largest concentration gradients (in the vertical and in change with time). In the COMET model it is assumed that the mixed layer is homogeneous. In the existence of large vertical gradients and in modelling the exchange between mixed 10 layer and reservoir layer when the mixed layer grows, we expect that the COMET model will make a only small error, as the average additional mass of $\mathrm{CH}_{4}$ does not change. In the night time case with a mixed layer depth lowering in time and large gradients, the COMET model will however overestimate the mass of $\mathrm{CH}_{4}$ that is dissolved into the reservoir layer. A possible improvement would be to apply in COMET a vertical concentration gradient as a function of atmospheric stability and the regional emission density for the stable night-time conditions. In the exchange process with the reservoir layer during lowering mixed layer depth only the mass of $\mathrm{CH}_{4}$ integrated over the top layer within the exchanged air mass is mixed into the reservoir layer. Application of this profile function above the receptor point will also most likely enhance the model performance for ground level observation sites like Mace Head. As the largest changes in concentrations occur in the final $24 \mathrm{~h}$ of transport before arrival at the receptor point, it is important to have the transport right in especially this final part of the trajectories. Higher resolution meteorological information will allow for some improvement, not only for the determination of transport direction and transport speed as a function of time and location, but more importantly also for the calculation of the local mixed layer height. Since February 2006 the ECMWF model resolution has been increased from 0.5 to 0.2 degrees, it is expected that this would lead to improved explained variability and further reduction of the RMSE of the predicted concentrations.

Another possible improvement would be the use of re-analysed data. Unfortunately

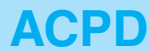

$6,8727-8779,2006$

The COMET transport model applied to methane

A. T. Vermeulen et al.

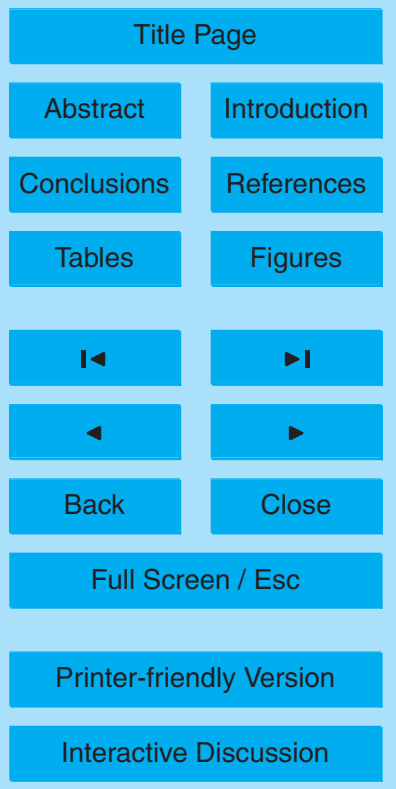


the current availability of re-analysis data from the ECMWF model (ERA-40) ends at September 2002 (Uppala et al., 2005). From analyses (e.g. A. Beljaars, personal communication, 2006) it is known that ECMWF analysed data can have quite significant systematic errors in wind speeds end directions when compared to surface and balloon 5 sonde observations, leading to substantial accumulating errors in trajectory positions, and in mixed layer heights. Re-analysed data improve both the systematic and random errors in the important parameters. Recent tests using ERA-40 data for the summer months of 2002 in the COMET framework however did not show a big improvement in model skill for the methane concentrations at Cabauw.

Acknowledgements. The authors would like to thank KNMI for hosting the measurements at Cabauw tower. ECMWF and KNMI are acknowledged for the access to the ECMWF MARS meteorological archive. Financial support for this research has come from the Ministry of VROM, Novem/Senter and the European Commission (CarboEurope-IP and CHIOTTO projects).

\section{References}

Berdowski, J. J. M., Draaijers, G. P. J., Janssen, L. H. J. M., Hollander, J. C. T., Loon, M. v., Roemer, M. G. M., Vermeulen, A. T., Vosbeek, M., and Visser, H.: Independent Checks for Validation of Emission Estimates: The METDAT Example for Methane, Tech. Rep. P98/037, TNO, Apeldoorn, The Netherlands, 1998. 8736, 8745, 8746

Bergamaschi, P., Krol, M., Dentener, F., Vermeulen, A. T., Meinhardt, F., Graul, R., Ramonet, M., Peters, W., and Dlugokencky, E.: Inverse modelling of national and European $\mathrm{CH}_{4}$ emissions using the atmospheric zoom model TM5, Atmos. Chem. Phys., 5, 2431-2460, 2005. 8731

Biraud, S., Ciais, P., Ramonet, M., Simmonds, P., Kazan, V., Monfray, P., O’Doherty, S., Spain, T. G., and Jennings, S. G.: European greenhouse gas emissions estimated from continuous atmospheric measurements and radon ${ }^{222}$ at Mace Head, Ireland, J. Geophys. Res.-Atmos., 105, 1351-1366, 2000. 8745

Bousquet, P., Ciais, P., Monfray, P. Y. B., and M. R.: Influence of two atmospheric transport models on inferring sources and sinks of atmospheric $\mathrm{CO}_{2}$, Tellus, 48B, 568-582, 1996. 8731

The COMET transport model applied to methane

A. T. Vermeulen et al.

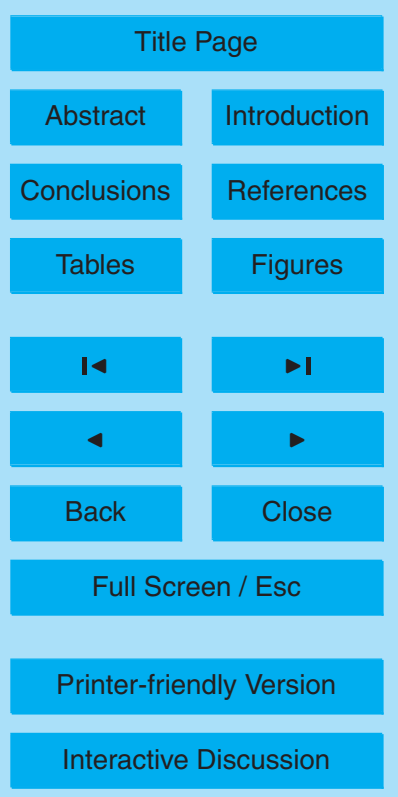

EGU 
Bousquet, P., Ciais, P., Peylin, P., Ramonet, M., and Monfray, P.: Inverse modeling of annual atmospheric $\mathrm{CO} 2$ sources and sinks 1 . Method and control inversion, J. Geophys. Res.Atmos., 104, $26161-26178,1999.8730$

Bousquet, P., Peylin, P., Ciais, P., Le Quere, C., Friedlingstein, P., and Tans, P. P.: Regional changes in carbon dioxide fluxes of land and oceans since 1980, Science, 290, 1342-1346, 2000. 8730

Broecker, W. S.: Thermohaline circulation, the Achilles heel of our climate system: Will manmade $\mathrm{CO}_{2}$ upset the current balance?, Science, 278, 1582-1588, 1997. 8728

Conway, T., Tans, P., Waterman, L., Thoning, K., Kitzis, D., Masarie, K., and Zhang, N.: Evidence for interannual variability of the carbon cycle from the national oceanic and atmospheric administration climate monitoring and diagnostics laboratory global air sampling network, J. Geophys. Res., 99, 22 831-22 855, 1994. 8730

Eisma, R., Vermeulen, A., and Van der Borg, K.: ${ }^{14} \mathrm{CH}_{4}$ Emissions from Nuclear Power Plants in Northwestern Europe, Radiocarbon, 37(2), 475-483, 1995. 8733

15 Fan, S., Gloor, M., Mahlman, J., Pacala, S., Sarmiento, J., Takahashi, T., and Tans, P.: A large terrestrial carbon sink in North America implied by atmospheric and oceanic carbon dioxide data and models, Science, 282, 442-446, 1998. 8730

GLOBALVIEW- $\mathrm{CO}_{2}$ : Cooperative Atmospheric Data Integration Project - Carbon Dioxide, CDROM, NOAA CMDL, Boulder, Colorado, ftp://ftp.cmdl.noaa.gov, ccg/co2/GLOBALVIEW, $20 \quad$ 2004. 8730, 8752

Gurney, K. R., Law, R. M., Denning, A. S., Rayner, P. J., Baker, D., Bousquet, P., Bruhwiler, L., Chen, Y. H., Ciais, P., Fan, S., Fung, I. Y., Gloor, M., Heimann, M., Higuchi, K., John, J., Maki, T., Maksyutov, S., Masarie, K., Peylin, P., Prather, M., Pak, B. C., Randerson, J., Sarmiento, J., Taguchi, S., Takahashi, T., and Yuen, C. W.: Towards robust regional estimates of CO2 sources and sinks using atmospheric transport models, Nature, 415, 626-630, 2002. 8730, 8731

Heimann, M.: The global atmospheric transport model TM2, Tech. Rep. 10, Max Planck-Inst. für Meteorologie, Hamburg, 1996. 8734

Heimann, M. and Kaminski, T.: Inverse modelling approaches to infer surface trace gas fluxes 30 from observed atmospheric mixing ratios, in: Approaches to scaling of trace gas fluxes in ecosystems, edited by: Bouwman, A. F., 277-295, Elsevier, Amsterdam, ISBN 0-444-829342, 1999. 8730

Houghton, J. T., Ding, Y., Griggs, D. J., Noguer, M., van der Linden, P. J., and Xiaosu, D.:

The COMET transport model applied to methane

A. T. Vermeulen et al.

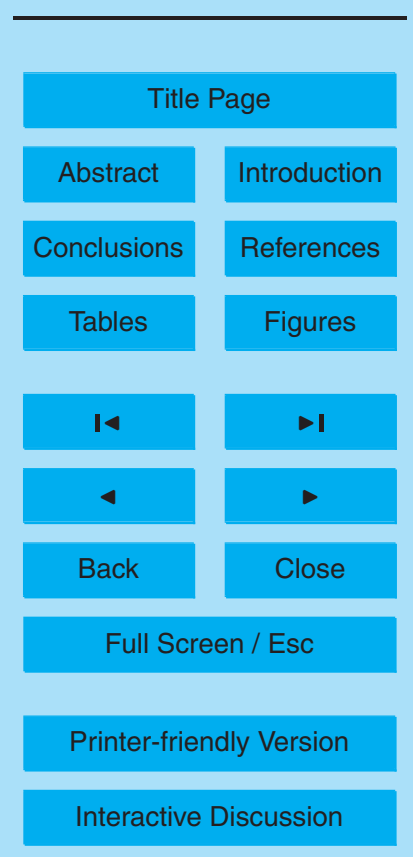


Climate Change 2001: The Scientific Basis, Cambridge University press, 2001. 8728, 8729 Houweling, S., Kaminski, T., Dentener, F., Lelieveld, J., and Heimann, M.: Inverse modeling of methane sources and sinks using the adjoint of a global transport model, J. Geophys. Res.-Atmos., 104, 26 137-26 160, 1999. 8734, 8747

5 Keppler, F., Hamilton, J. T. G., Brass, M., and Röckmann, T.: Methane emissions from terrestrial plants under aerobic conditions, Nature, 439, 187-191, 2006. 8729

Law, R. M., Rayner, P. J., Denning, A. S., Erickson, D., Fung, I. Y., Heimann, M., Piper, S. C., Ramonet, M., Taguchi, S., Taylor, J. A., Trudinger, C. M., and Watterson, I. G.: Variations in modeled atmospheric transport of carbon dioxide and the consequences for $\mathrm{CO}_{2}$ inversions,

$10 \quad$ Global Biogeochem. Cycles, 10, 783-796, 1996. 8731

Lighthill, J.: The recently recognized failure of predictability in Newtonian dynamics, Proc. R. Soc. London, A 407, 35-48, 1986. 8732

Olivier, J., Bouwman, A., Van der Maas, C., Berdowski, J., Veldt, C., Bloos, J., Visschedijk, A., Zandveld, P., and Haverlag, J.: Description of EDGAR Version 2.0. A set of global emission inventories of greenhouse gases and ozone-depleting substances for all anthropogenic and most natural sources on a per country basis and on $1^{\circ} \times 1^{\circ}$ grid, Tech. Rep. 771060002 , RIVM, Bilthoven, 1996. 8745

Pine, D. J., Gollub, J. P., Brady, J. F., and Leshansky, A. M.: Chaos and threshold for irreversibility in sheared suspensions, Nature, 438, 997-1000, 2005. 8732

20 Press, W. H., Teukolsky, S. A., Vetterling, W. T., and P., F. B.: Numerical Recipes, Cambridge University Press, Cambridge, 1992. 8737

Prinn, R., Weiss, R., Fraser, P., Simmonds, P., Cunnold, D., Alyea, F., O’Doherty, S., Salameh, P., Miller, B., Huang, J., Wang, R., Hartley, D., Harth, C., Steele, L., Sturrock, G., Midgely, P., and A., M.: A history of chemically and radiatively important gases in air deduced from ALE/GAGE/AGAGE, J. Geophys. Res., 105, 17751-17792, 2000. 8745, 8747

Prinn, R. G., Weiss, R. F., Miller, B. R., Huang, J., Alyea, F. N., Cunnold, D. M., Fraser, F. J., Hartley, D. E., and Simmonds, P. G.: Atmospheric trend and lifetime of $\mathrm{CH}_{3} \mathrm{CCl}_{3}$ and global OH concentrations, Science, 269, 187-192, 1995. 8729

Rayner, P., Enting, I., Francey, R., and Langenfelds, R.: Reconstructing the recent carbon cycle from atmospheric $\mathrm{CO}_{2},{ }^{13} \mathrm{CO}_{2}$, and $\mathrm{O}_{2} / \mathrm{N}_{2}$ observations, Tellus $\mathrm{B}, 51,213-232,1999.8730$

Riccio, A., Barone, G., Chinese, E., and Giunta, G.: A hierarchical Bayesian approach to the spatio-temporal modeling of air quality data, Atm. Env., 40, 554-566, 2006. 8731

Ridgwell, A. J., Marshall, S. J., and Gregson, K.: Consumption of methane by soils: A process-

The COMET transport model applied to methane

A. T. Vermeulen et al.

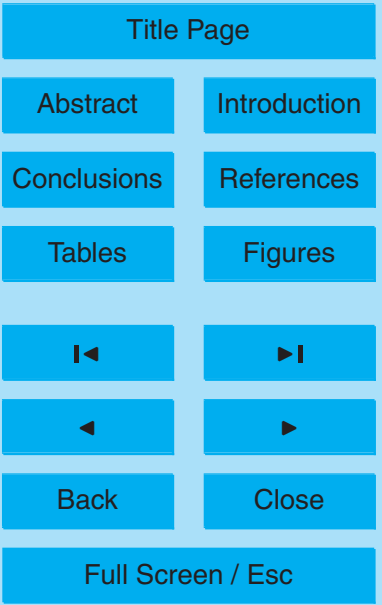

Printer-friendly Version

Interactive Discussion 
based model, Global Biogeochem. Cycles, 13, 59-70, 1999. 8729

Rödenbeck, C., Houweling, S., Gloor, M., and Heimann, M.: $\mathrm{CO}_{2}$ flux history 1982-2001 inferred from atmospheric data using a global inversion of atmospheric transport, Atmos. Chem. Phys., 3, 1919-1964, 2003. 8730

5 Simmonds, P. G., Derwent, R. G., McCulloch, A., O'Doherty, S., and Gaudry, A.: Long-term trends in concentrations of halocarbons and radiatively active trace gases in Atlantic and European air masses monitored at Mace Head, Ireland from 1987-1994, Atmos. Environ., 30, 4041-4063, 1996. 8745

Stohl, A. and Thomson, D. J.: A density correction for Lagrangian particle dispersion models, Boundary-Layer Meteorology, 90, 155-167, 1999. 8734 for simple back trajectory calculations in the interpretation of atmospheric trace substance measurements, Atmos. Env., 36, 4648, 2002. 8732, 8735

Stohl, A., Forster, C., Frank, A., Seibert, P., and Wotawa, G.: Technical note: The Lagrangian 15 particle dispersion model FLEXPART version 6.2, Atmos. Chem. Phys., 5, 2461-2474, 2005. 8735

Stull, R. B.: An Introduction to Boundary Layer Meteorology, vol. 13 of Atmospheric and Oceanographic Sciences Library, Kluwer Academic Publishers, Norwell, 1988. 8736

Uppala, S. M., Kallberg, P. W., Simmons, A. J., Andrae, U., Bechtold, V. D., Fiorino, M., Gibson, J. K., Haseler, J., Hernandez, A., Kelly, G. A., Li, X., Onogi, K., Saarinen, S., Sokka, N., Allan, R. P., Andersson, E., Arpe, K., Balmaseda, M. A., Beljaars, A. C. M., Van De Berg, L., Bidlot, J., Bormann, N., Caires, S., Chevallier, F., Dethof, A., Dragosavac, M., Fisher, M., Fuentes, M., Hagemann, S., Holm, E., Hoskins, B. J., Isaksen, L., Janssen, P., Jenne, R., McNally, A. P., Mahfouf, J. F., Morcrette, J. J., Rayner, N. A., Saunders, R. W., Simon, P., Sterl, A., Trenberth, K. E., Untch, A., Vasiljevic, D., Viterbo, P., and Woollen, J.: The ERA-40 re-analysis, Quart. J. Royal Meteorol. Soc., 131, 2961-3012, part B, 2005. 8757

Vermeulen, A. T., Eisma, R., Hensen, A., and Slanina, J.: Transport model calculations of NW-European methane emissions, Environ. Sci. Policy, 2, 315-324, 1999. 8733

Vermeulen, A. T., Loon, M. v., Builtjes, P. J. H., and Erisman, J. W.: Inverse transport modeling 30 of non- $\mathrm{CO}_{2}$ greenhouse gas emissions of Europe, in: Air Pollution Modeling and its Applications XIV, edited by: Gryning, S. and Schiermeier, F. A., 631-640, Kluwer, New York, 2001. 8732,8733

The COMET transport model applied to methane

A. T. Vermeulen et al.

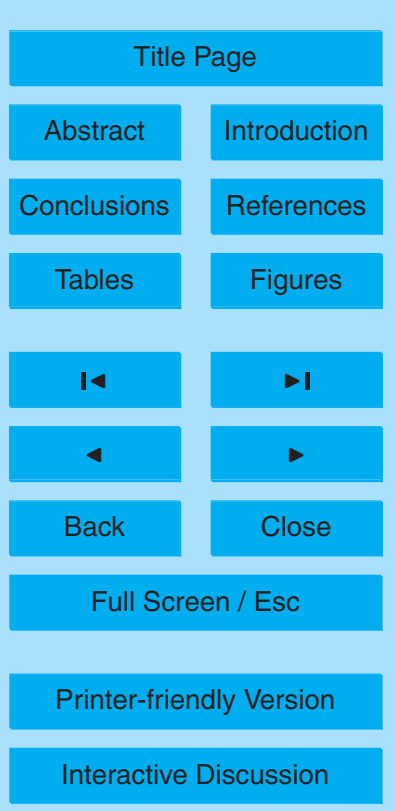




\section{ACPD}

\section{6, 8727-8779, 2006}

The COMET transport model applied to methane

A. T. Vermeulen et al.

Table 1. Percentage of $\mathrm{CH}_{4}$ emissions for the main source categories in 1994 for The Netherlands and NW-Europe.

\begin{tabular}{lrr}
\hline Category & NL & NW-Europe \\
\hline enteric fermentation & 29.2 & 38.3 \\
landfills & 28.4 & 29.7 \\
animal waste & 11.8 & 6.5 \\
gas distribution & 6.9 & 4.4 \\
coal mining & 0.0 & 19.1 \\
other & 6.3 & 11.1 \\
\hline
\end{tabular}

Title Page

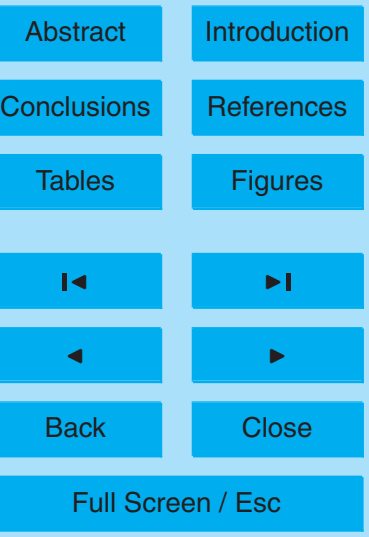

Printer-friendly Version

Interactive Discussion 


\section{ACPD}

6, 8727-8779, 2006

\section{The COMET transport model applied to methane}

A. T. Vermeulen et al.

Table 2. Resolution and dimensions of the three nested grids of the meteorological information from the ECMWF model.

\begin{tabular}{llrrrr}
\hline Grid index & Resol. $\left[^{\circ}\right]$ & Lon $\left[^{\circ}\right]$ & Lat $\left[^{\circ}\right]$ & Lon $\left[^{\circ}\right]$ & Lat $\left[^{\circ}\right]$ \\
\hline 0 & 2.0 & -178 & 0 & 180 & 90 \\
1 & 1.0 & -50 & 25 & 50 & 75 \\
2 & 0.5 & -20 & 35 & 30 & 60 \\
\hline
\end{tabular}

Title Page

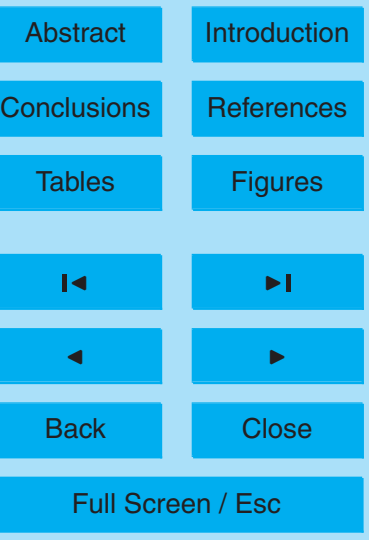

Printer-friendly Version

Interactive Discussion 
Table 3. Result of performance tests for COMET using different types of trajectory information. Case 1 is the standard case. See text for explanation.

\section{$6,8727-8779,2006$}

The COMET transport model applied to methane

A. T. Vermeulen et al.

\begin{tabular}{llrrrr}
\hline Case & Traj. type & $\mathrm{R}^{2}$ & $\mathrm{a}$ & $\mathrm{b}$ & $\mathrm{RMSE}$ \\
\hline 1 & 3-D 20 m & 0.7117 & 1.039 & -11 & 140 \\
2 & 3-D 60 m & 0.6952 & 0.967 & -14 & 136 \\
3 & 3-D 120 m & 0.6712 & 0.909 & -14 & 135 \\
4 & 200 m & 0.6494 & 0.867 & -13 & 136 \\
5 & Mix 20 m & 0.7040 & 1.050 & -4 & 145 \\
6 & Clust. A & 0.7049 & 1.086 & -10 & 149 \\
7 & Clust. B & 0.6916 & 1.129 & -4 & 160 \\
8 & Clust. C & 0.6951 & 1.063 & -11 & 149 \\
9 & Clust. D & 0.7041 & 0.973 & -14 & 133 \\
10 & Clust. E & 0.6938 & 0.955 & -13 & 134 \\
11 & Emis time var. & 0.7148 & 1.039 & -12 & 139 \\
12 & High resolution & 0.7129 & 0.882 & -11 & 115 \\
\hline
\end{tabular}

Title Page

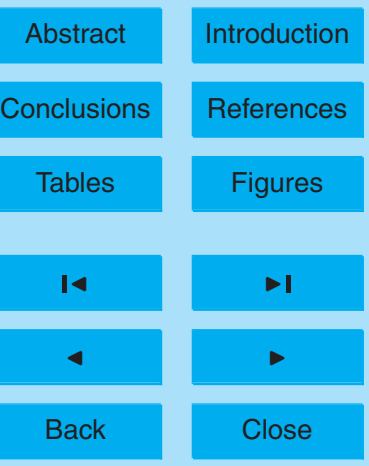

Full Screen / Esc

Printer-friendly Version

Interactive Discussion 
Table 4. Linear regression results of COMET modelled versus measured concentrations for 2002 at Cabauw as a function of the diameters of the Region of Influence around the trajectory positions.

\section{ACPD}

6, 8727-8779, 2006

The COMET transport model applied to methane

A. T. Vermeulen et al.

Title Page

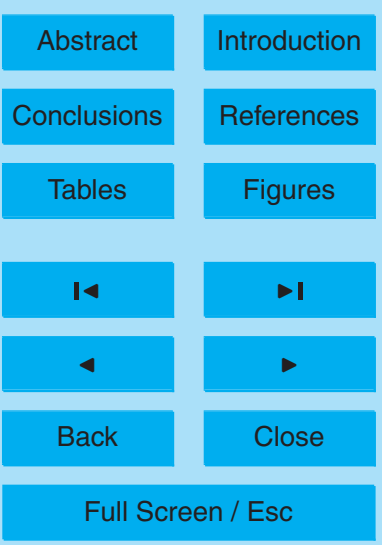

Printer-friendly Version

Interactive Discussion 


\section{ACPD}

6, 8727-8779, 2006

The COMET transport model applied to methane

Table 5. Correlation $\left(\mathrm{R}^{2}\right)$ and RMSE of COMET 2002 forward predicted $\mathrm{CH}_{4}$ hourly concentrations compared to the observed mixed layer concentration as a function of reservoir layer height.

\begin{tabular}{lrrrr}
\hline Res. hght[m] & a[ppm/ppm] & b[ppm] & $\mathrm{R}^{2}$ & RMSE[ppm] \\
\hline 10000 & 1.037 & -0.01 & 0.7067 & 0.1412 \\
9000 & 1.038 & -0.009 & 0.7069 & 0.1413 \\
8000 & 1.039 & -0.009 & 0.7072 & 0.1413 \\
7000 & 1.04 & -0.008 & 0.7074 & 0.1414 \\
6000 & 1.042 & -0.007 & 0.7078 & 0.1414 \\
5000 & 1.044 & -0.006 & 0.7083 & 0.1416 \\
4000 & 1.048 & -0.003 & 0.7089 & 0.1418 \\
3000 & 1.053 & 0 & 0.7097 & 0.1424 \\
\hline
\end{tabular}

Title Page

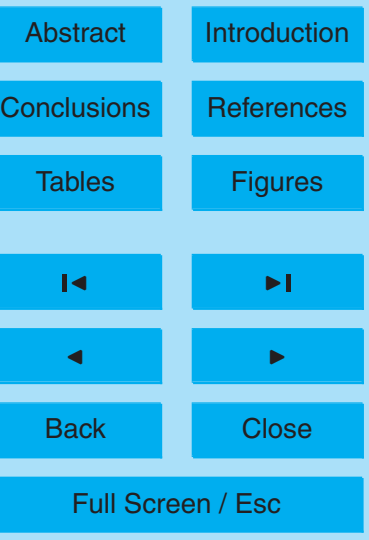

Printer-friendly Version

Interactive Discussion 


\section{ACPD}

6, 8727-8779, 2006

The COMET transport model applied to methane

Table 6. Performance of the COMET model as a function of the backward length of the trajectory data for a range of 12 to $96 \mathrm{~h}$ ( $\mathrm{a}=$ slope of linear regression line, $\mathrm{R}^{2}=$ correlation coefficient, RMSE=Root Mean Square error).

\begin{tabular}{lrrr}
\hline Traj. backward length [hr] & $\mathrm{a}$ [ppm] & $\mathrm{R}^{2}$ & $\mathrm{RMSE}$ [ppm] \\
\hline 96 & 1.039 & 0.7064 & 0.142 \\
84 & 1.035 & 0.7035 & 0.142 \\
72 & 1.027 & 0.6991 & 0.143 \\
60 & 1.019 & 0.6949 & 0.143 \\
48 & 1.008 & 0.6880 & 0.144 \\
36 & 0.993 & 0.6782 & 0.146 \\
24 & 0.960 & 0.6694 & 0.145 \\
12 & 0.846 & 0.6283 & 0.139 \\
\hline
\end{tabular}

A. T. Vermeulen et al.

Title Page

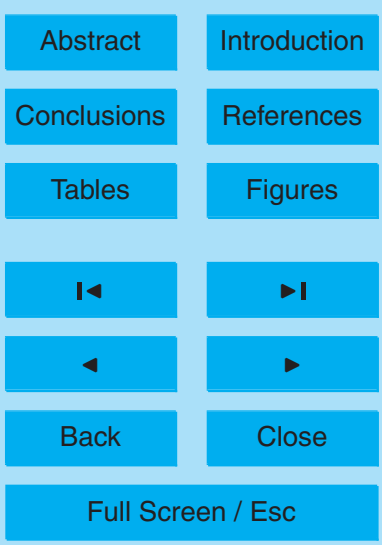

Printer-friendly Version

Interactive Discussion 


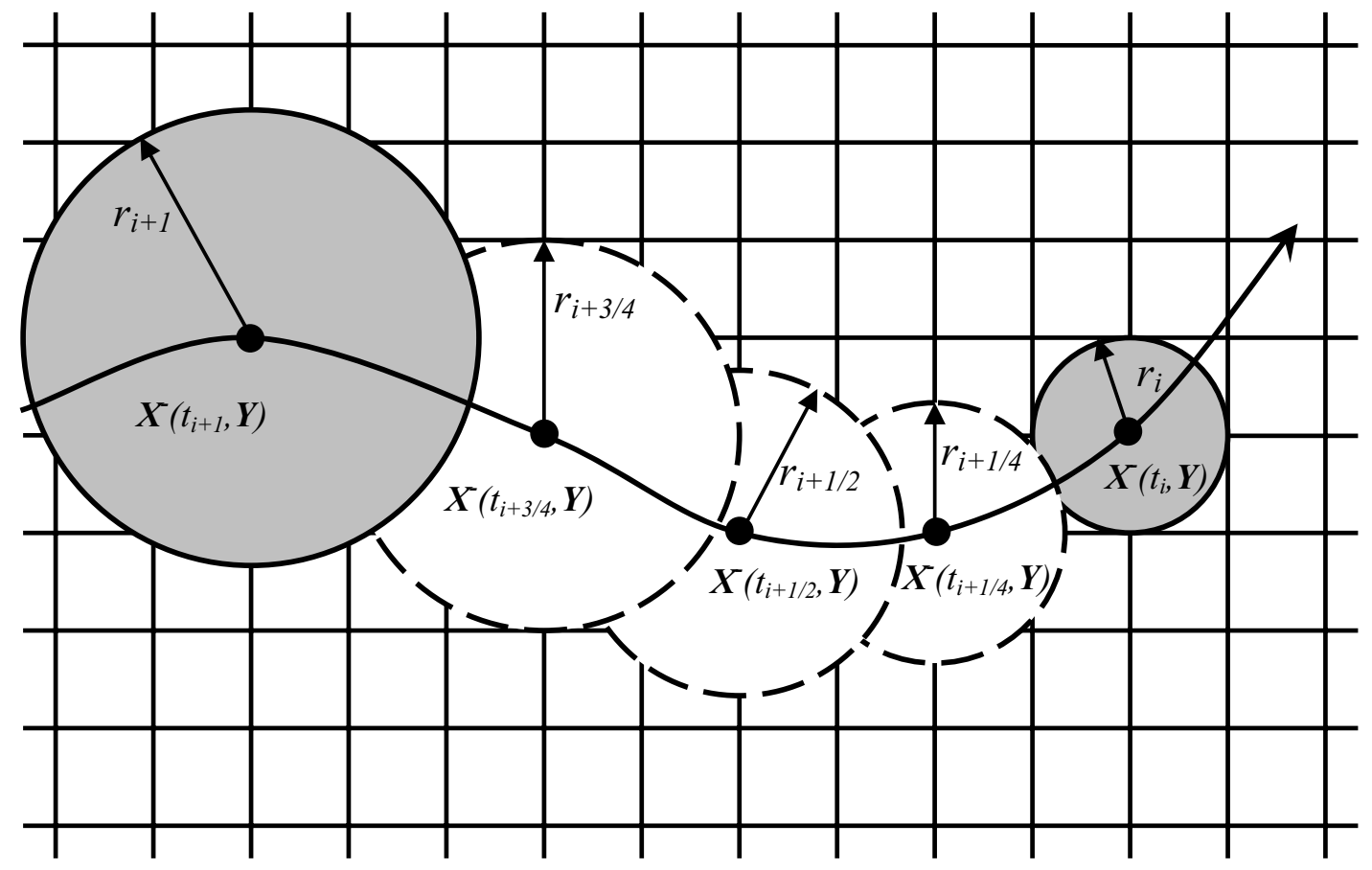

Fig. 1. Illustration of the two layer column evolution along a trajectory in the COMET model.

\section{6, 8727-8779, 2006}

The COMET transport model applied to methane

A. T. Vermeulen et al.

Title Page

Abstract

Introduction

Conclusions

References

Tables

Figures

14

$\rightarrow 1$

$\triangleleft$

Back

Close

\section{Full Screen / Esc}

Printer-friendly Version

Interactive Discussion

EGU 


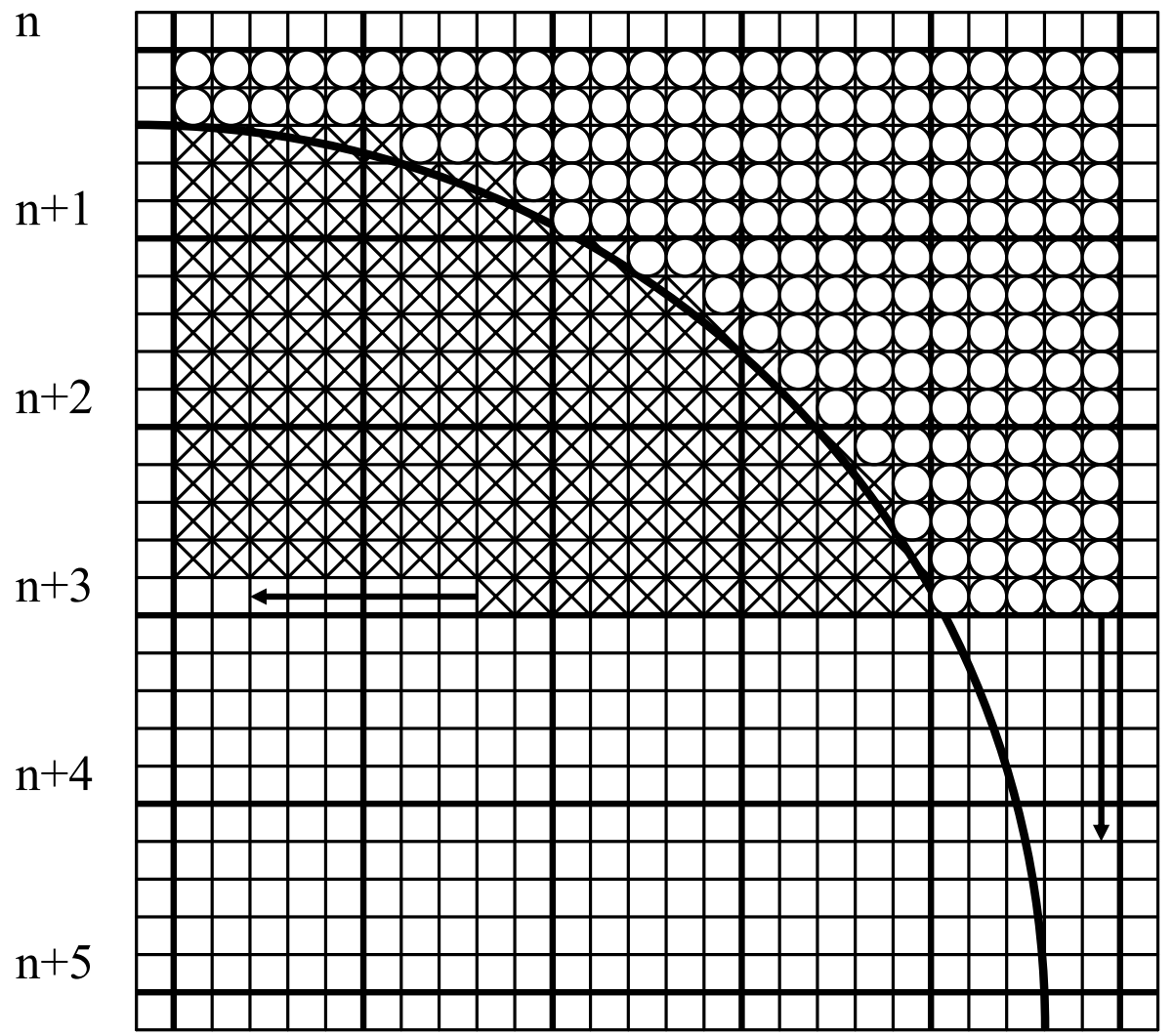

6, 8727-8779, 2006

The COMET transport model applied to methane

A. T. Vermeulen et al.

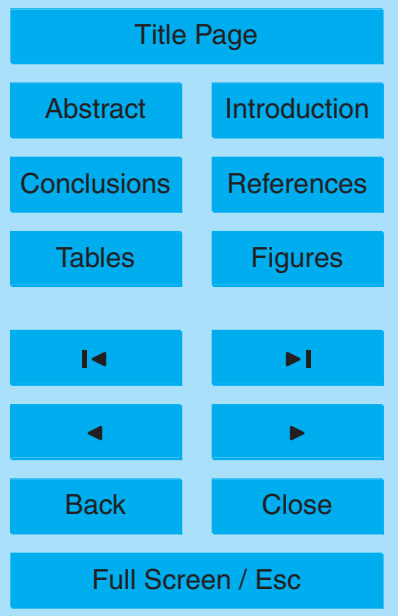

Fig. 2. Illustration of the source grid scanning procedure.

Printer-friendly Version

Interactive Discussion

EGU 


\section{ACPD}

\section{6, 8727-8779, 2006}

The COMET transport model applied to methane

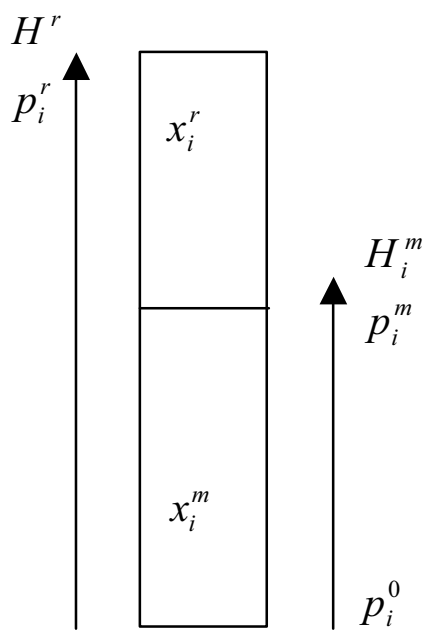

Initial state

$$
H^{r}
$$$$
p_{i+\delta}^{r}
$$
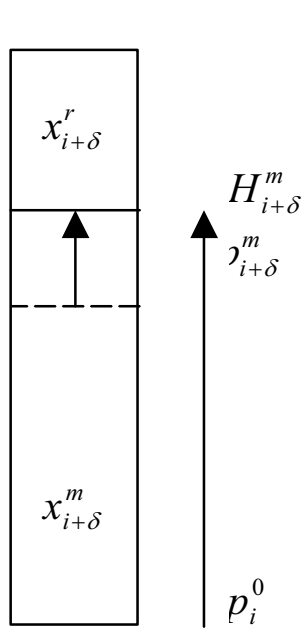

After build-up

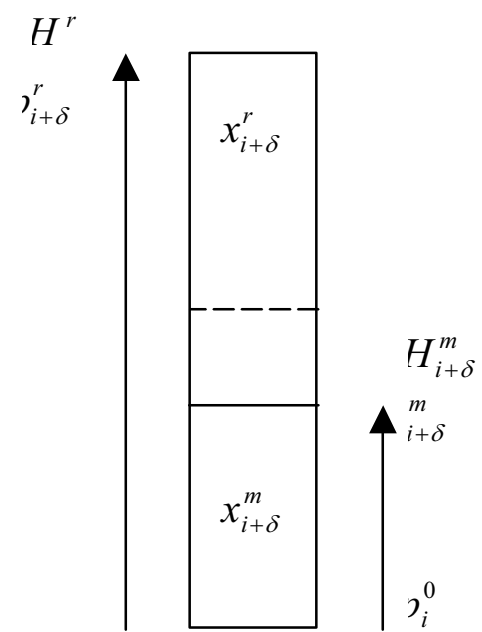

After break-down

A. T. Vermeulen et al.

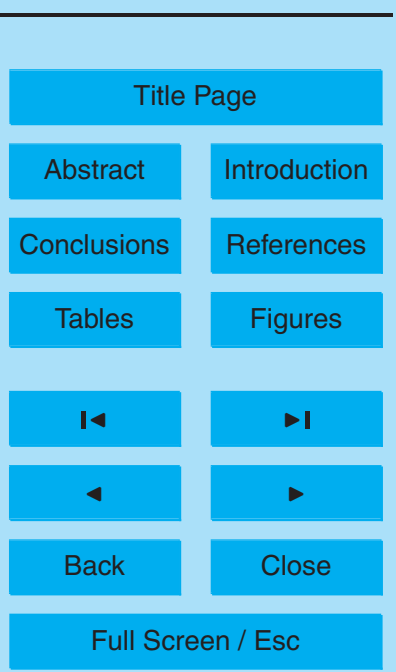

Fig. 3. Illustration of the three column states of the COMET model: no change, growth and shrinkage of the mixed layer. 


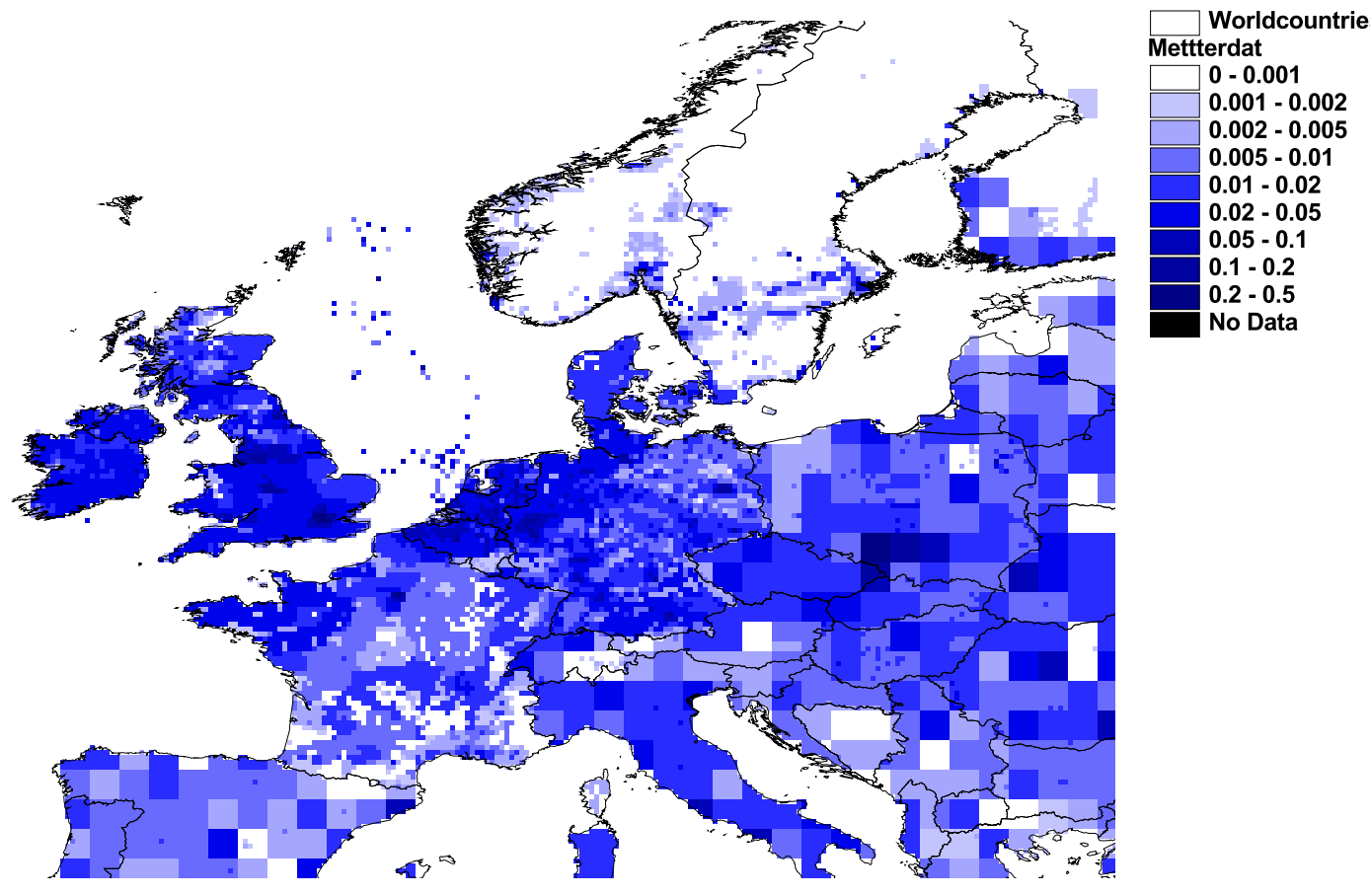

\section{ACPD}

6, 8727-8779, 2006

The COMET transport model applied to methane

A. T. Vermeulen et al.

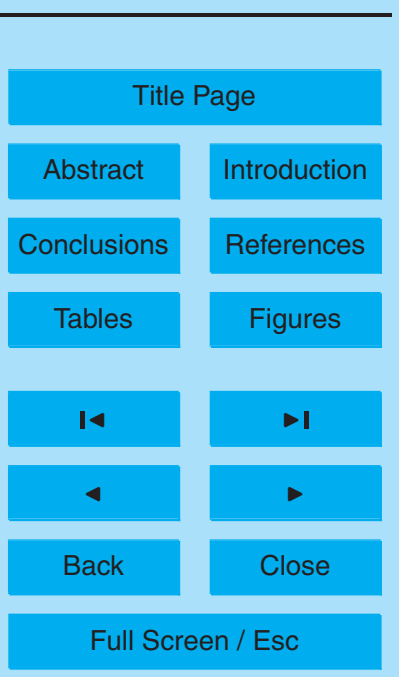

Fig. 4. METDAT annual mean emissions of methane in $\mathrm{g} \mathrm{m}^{-2} \mathrm{yr}^{-1}$.

Printer-friendly Version

Interactive Discussion 


\section{ACPD}

\section{$6,8727-8779,2006$}

The COMET transport model applied to methane

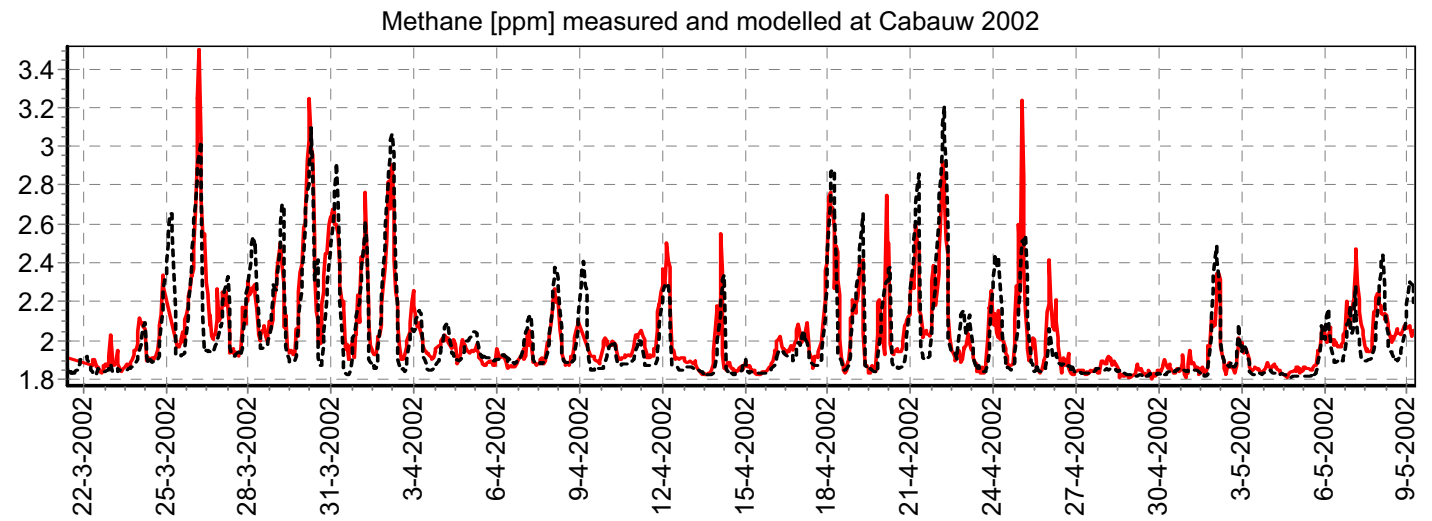

A. T. Vermeulen et al.

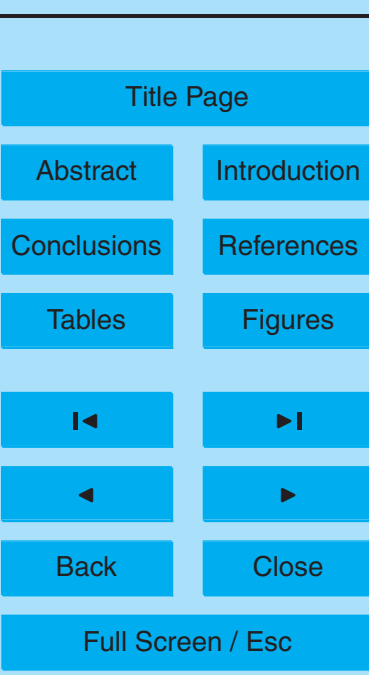

Fig. 5. Hourly mixed layer average $\mathrm{CH}_{4}$ concentration (ppm) at Cabauw in 2002, 22 March-9 May as measured (red solid line) and modelled (black dashed line) with the COMET model in forward mode. 


\section{ACPD}

6, 8727-8779, 2006

The COMET transport model applied to methane

Methane [ppm] measured and modelled at macehead 2002

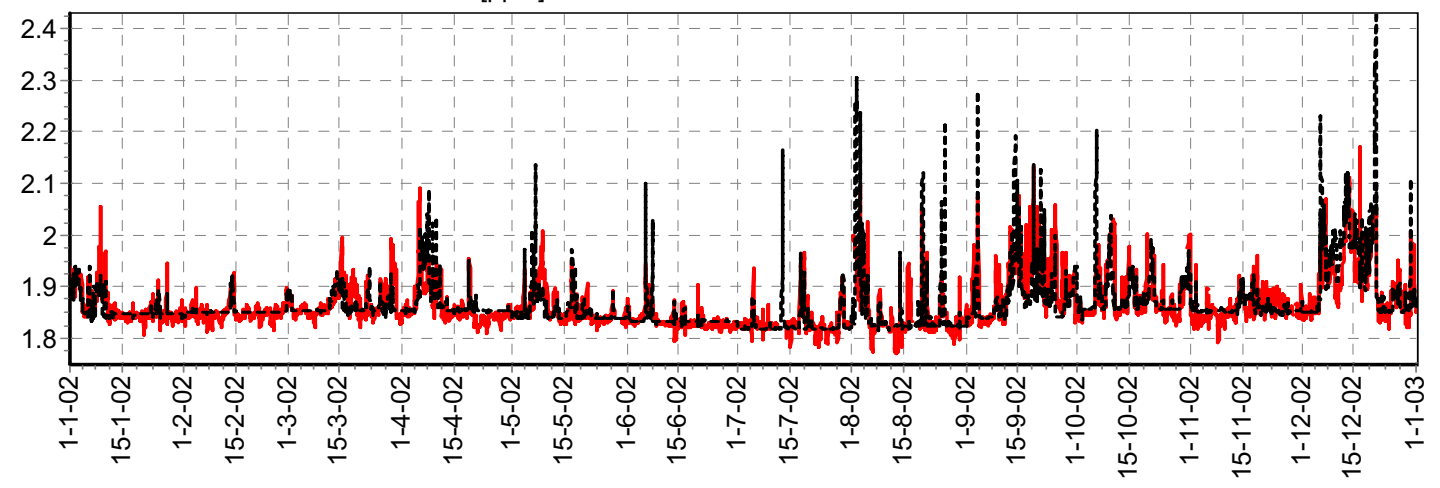

Fig. 6. Mace Head measured (red solid line) versus COMET (black dashed line) forward modelled $\mathrm{CH}_{4}$ concentrations [ppm], $\mathrm{R}^{2}=0.48$.
A. T. Vermeulen et al.

Title Page

Abstract

Introduction

Conclusions

References

Tables

Figures

14

4

Back

Full Screen / Esc

Printer-friendly Version

Interactive Discussion 


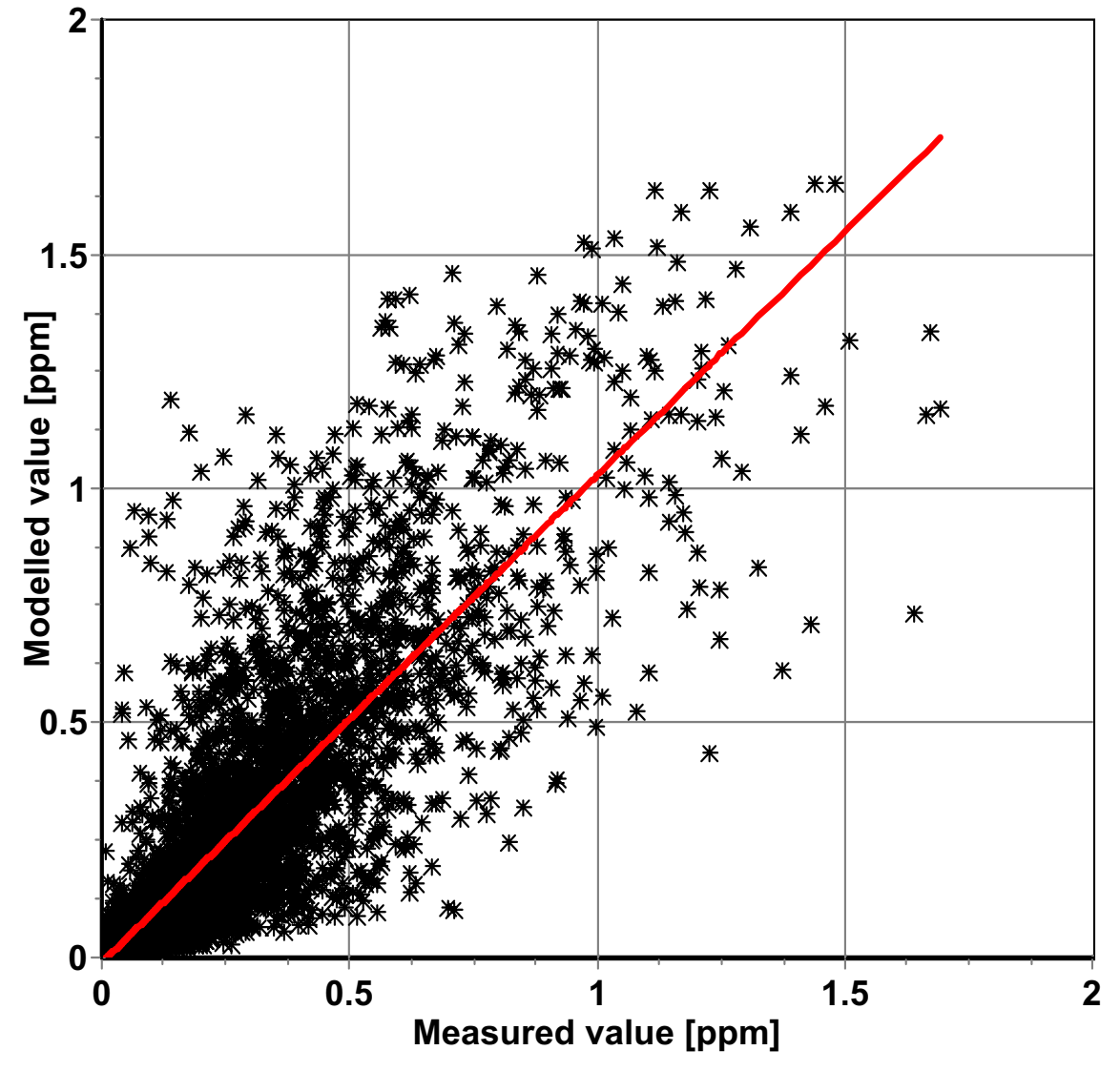

Fig. 7. Scatter plot of hourly predicted versus measured mixed layer concentrations of $\mathrm{CH}_{4}$ [ppm] for Cabauw, using the COMET model in forward mode and 3-D trajectory data for arrival at $20 \mathrm{~m}$ height a.g.l., standard settings.

\section{ACPD}

$6,8727-8779,2006$

The COMET transport model applied to methane

A. T. Vermeulen et al.

Title Page

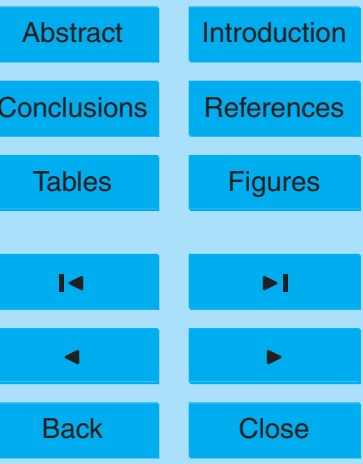

Full Screen / Esc

Printer-friendly Version

Interactive Discussion 


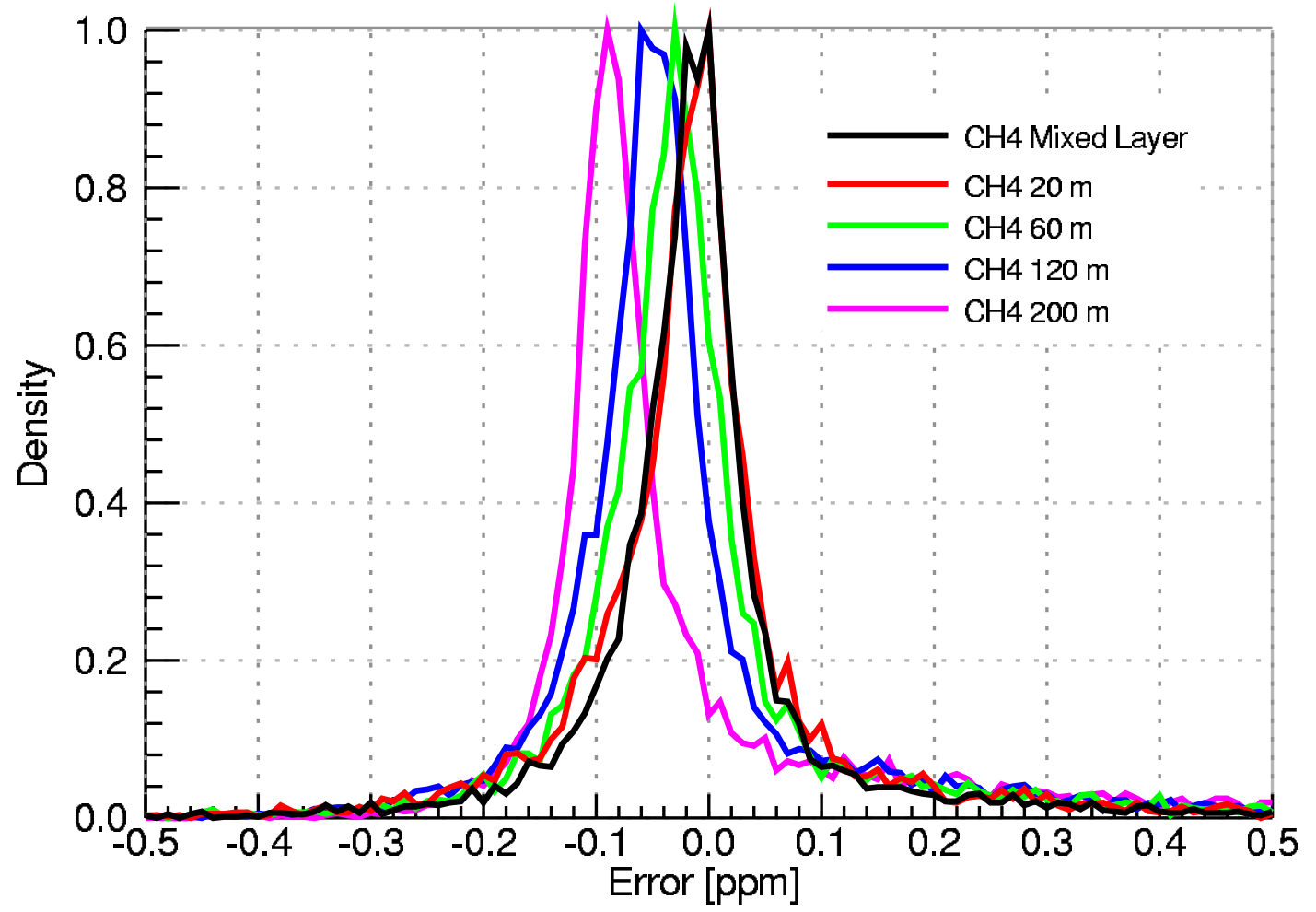

Fig. 8. Probability density of the error in the modelled hourly mixed layer average $\mathrm{CH}_{4}$ concentration (ppm) at Cabauw in 2002, when compared to the observations at the 4 measurement heights $(20,60,120,200 \mathrm{~m}$ a.g.l.) and the average mixed layer concentration (composed from the concentrations from these 4 levels).

\section{ACPD}

$6,8727-8779,2006$

The COMET transport model applied to methane

A. T. Vermeulen et al.

Title Page

Abstract

Introduction

Conclusions

References

Tables

Figures

14

4

Back

Close

Full Screen / Esc

Printer-friendly Version

Interactive Discussion 
COMET CBW 2002 Performance for $\mathrm{CH}_{4}$ as function of month, $1 \mathrm{hr}$ sample freq.

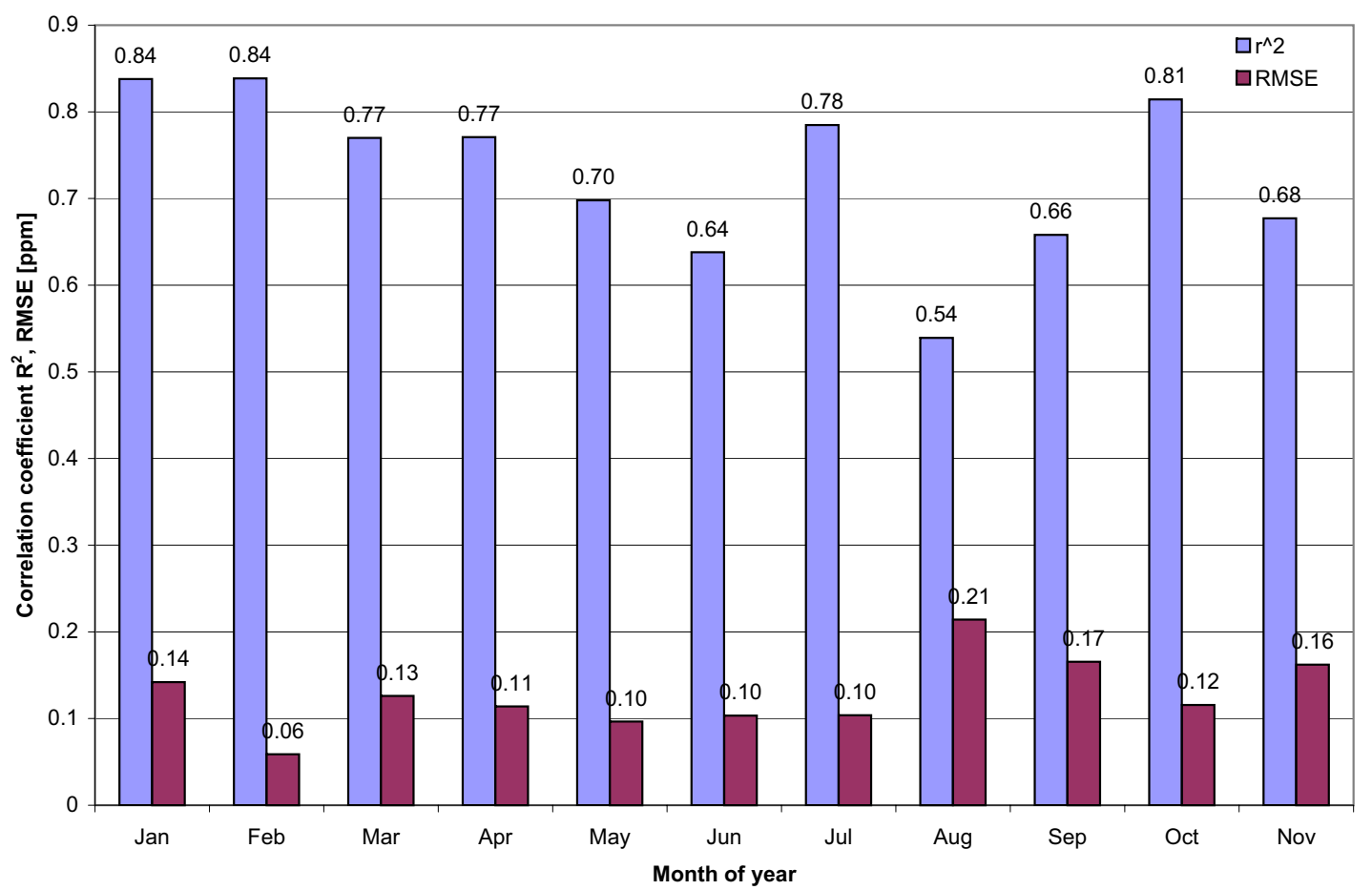

Fig. 9. Correlation $\left(\mathrm{R}^{2}\right)$ and RMSE [ppm] of COMET 2002 forward predicted $\mathrm{CH}_{4}$ hourly concentrations compared to the observed mixed layer concentration as a function of the month.

\section{ACPD}

$6,8727-8779,2006$

The COMET transport model applied to methane

A. T. Vermeulen et al.

Title Page

Abstract

Introduction

Conclusions

References

Tables

Figures

14

4

Back

Close

\section{Full Screen / Esc}

Printer-friendly Version

Interactive Discussion 
COMET CBW 2002 Performance for $\mathrm{CH}_{4}$ as function of time of day, $1 \mathrm{hr}$ sample freq.

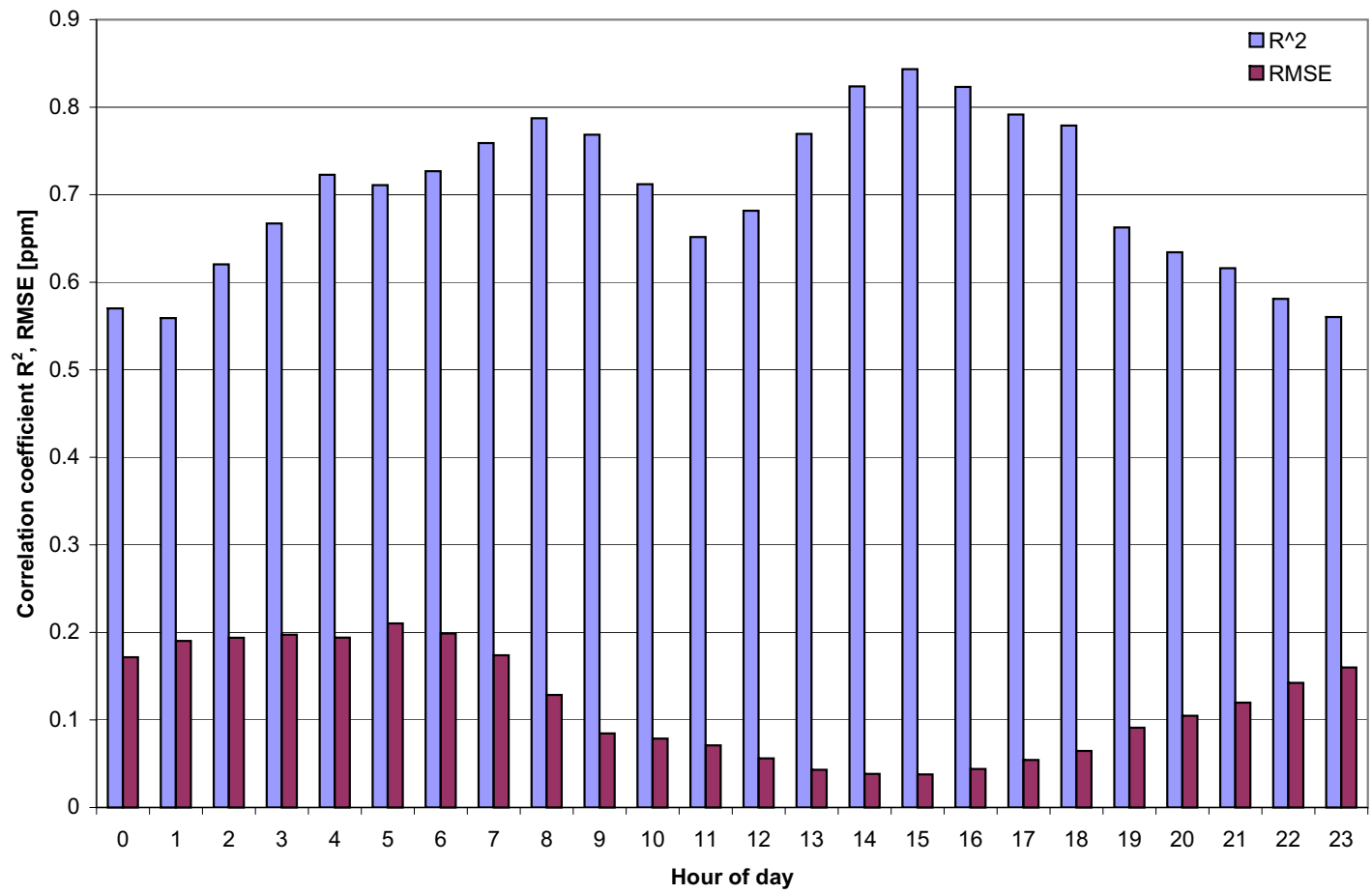

Fig. 10. Correlation $\left(\mathrm{R}^{2}\right)$ and RMSE [ppm] of COMET 2002 forward predicted $\mathrm{CH}_{4}$ hourly concentrations compared to the observed mixed layer concentration as a function of the hour of the day.
ACPD

6, 8727-8779, 2006

The COMET transport model applied to methane

A. T. Vermeulen et al.

Title Page

Abstract Introduction

Conclusions References

Tables

Figures

14

4

Back

Close

\section{Full Screen / Esc}

Printer-friendly Version

Interactive Discussion 
COMET CBW 2002 Performance for $\mathrm{CH}_{4}$ as function of averaging time

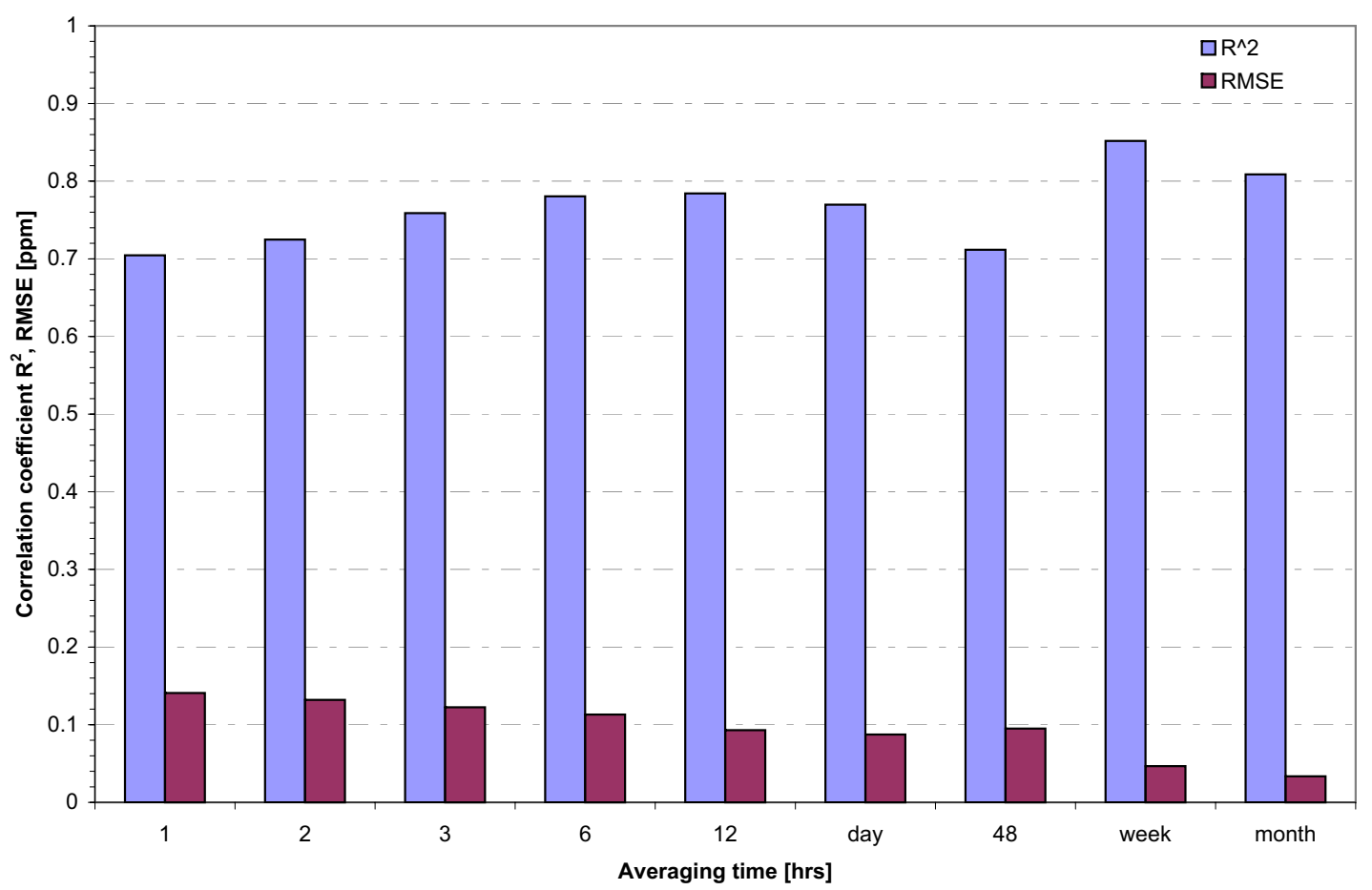

Fig. 11. Correlation $\left(\mathrm{R}^{2}\right)$ and RMSE [ppm] of COMET 2002 forward predicted hourly $\mathrm{CH}_{4}$ concentrations compared to the observed mixed layer concentration as a function of averaging time.

\section{ACPD}

$6,8727-8779,2006$

The COMET transport model applied to methane

A. T. Vermeulen et al.

Title Page

Abstract

Introduction

Conclusions

References

Tables

Figures

14

4

\section{Back}

Close

\section{Full Screen / Esc}

Printer-friendly Version

Interactive Discussion 
COMET CBW 2002 Performance for $\mathrm{CH}_{4}$ as function of averaging time for day time samples

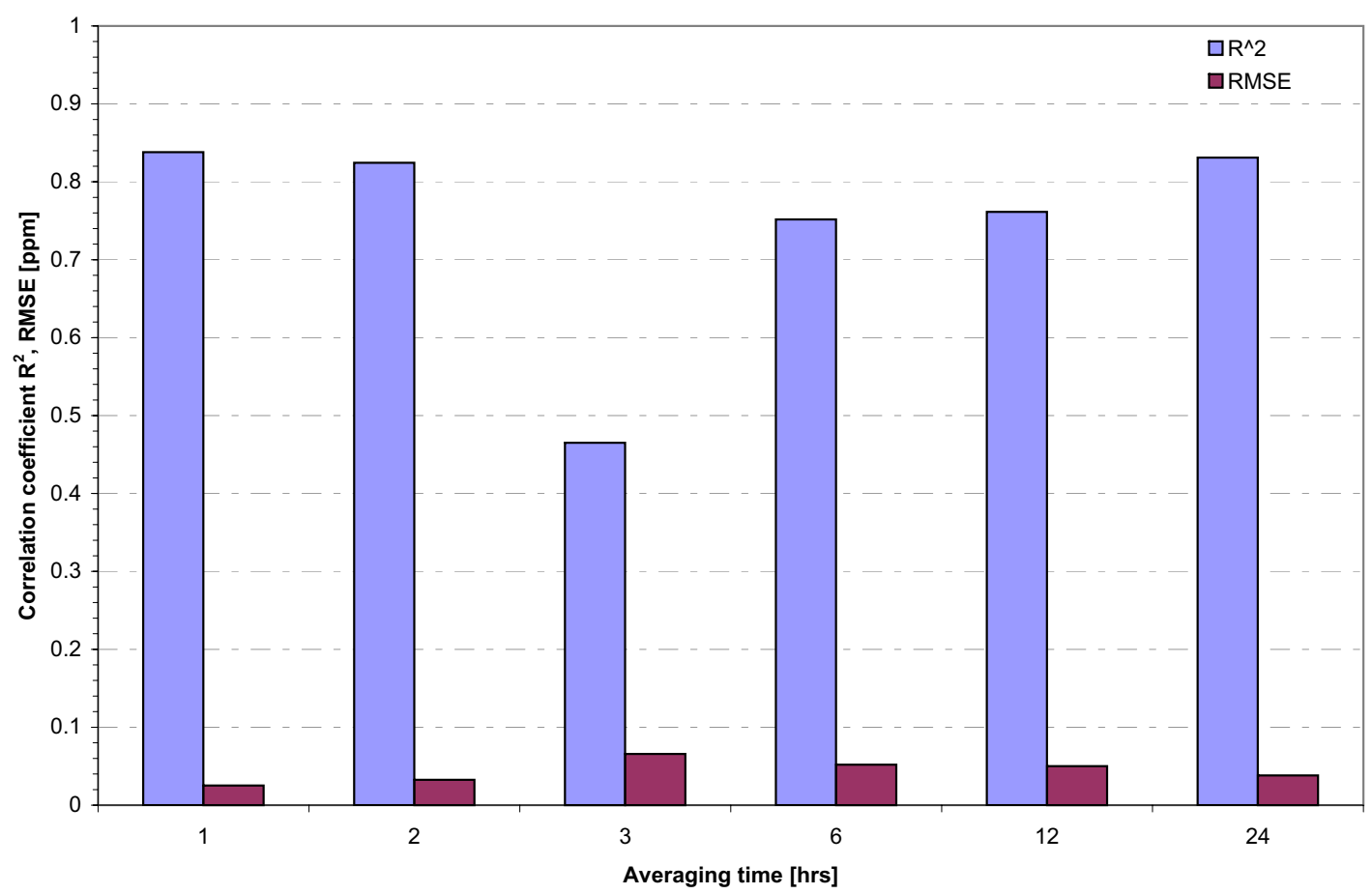

Fig. 12. Same as Fig. 11, but now for day time (12:00-17:00 UTC) sampled concentrations.
6, 8727-8779, 2006

The COMET transport model applied to methane

A. T. Vermeulen et al.

Title Page

Abstract

Introduction

Conclusions

References

Tables

Figures

14

4

\section{Back}

Close

\section{Full Screen / Esc}

Printer-friendly Version

Interactive Discussion 
COMET performance as function of methane emission resolution

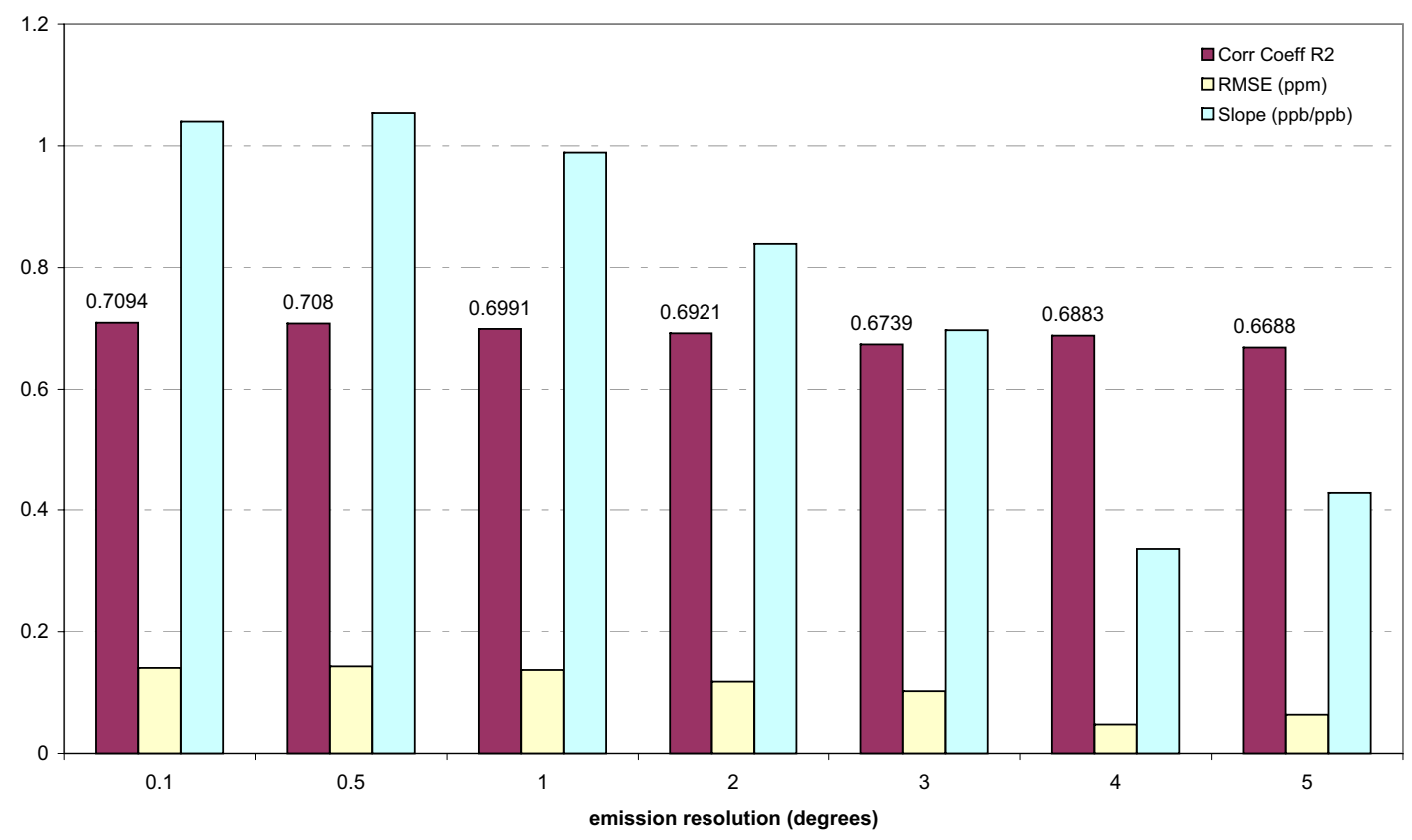

Fig. 13. Performance of COMET as a function of the resolution of the emission database, expressed as correlation coefficient $\left(\mathrm{R}^{2}\right)$, RMSE and slope of the regression line for the modelled versus observed mixed layer concentration.

\section{ACPD}

6, 8727-8779, 2006

The COMET transport model applied to methane

A. T. Vermeulen et al.

Title Page

Abstract Introduction

Conclusions References

Tables

Figures

14

4

\section{Back}

Close

\section{Full Screen / Esc}

Printer-friendly Version

Interactive Discussion 